\title{
Three new Diplozoidae mitogenomes expose unusual compositional biases within the Monogenea class: implications for phylogenetic studies
}

Dong Zhang ${ }^{1,2} \mathbb{D}$, Hong Zou', Shan G. Wu', Ming Li ${ }^{1}$, Ivan Jakovlić3 ${ }^{3}$ Jin Zhang ${ }^{3}$, Rong Chen ${ }^{3}$, Wen X. Li ${ }^{1}$ and Gui T. Wang ${ }^{1 *}$

\begin{abstract}
Background: As the topologies produced by previous molecular and morphological studies were contradictory and unstable (polytomy), evolutionary relationships within the Diplozoidae family and the Monogenea class (controversial relationships among the Discocotylinea, Microcotylinea and Gastrocotylinea suborders) remain unresolved. Complete mitogenomes carry a relatively large amount of information, sufficient to provide a much higher phylogenetic resolution than traditionally used morphological traits and/or single molecular markers. However, their implementation is hampered by the scarcity of available monogenean mitogenomes. Therefore, we sequenced and characterized mitogenomes belonging to three Diplozoidae family species, and conducted comparative genomic and phylogenomic analyses for the entire Monogenea class.

Results: Taxonomic identification was inconclusive, so two of the species were identified merely to the genus level. The complete mitogenomes of Sindiplozoon sp. and Eudiplozoon sp. are 14,334 bp and 15,239 bp in size, respectively. Paradiplozoon opsariichthydis (15,385 bp) is incomplete: an approximately 2000 bp-long gap within a non-coding region could not be sequenced. Each genome contains the standard 36 genes (atp8 is missing). $\mathrm{G}+\mathrm{T}$ content and the degree of GC- and AT-skews of these three mitogenome (and their individual elements) were higher than in other monogeneans. nad2, atp6 and nad6 were the most variable PCGs, whereas cox1, nad1 and cytb were the most conserved. Mitochondrial phylogenomics analysis, conducted using concatenated amino acid sequences of all PCGs, indicates that evolutionary relationships of the three genera are: (Eudiplozoon, (Paradiplozoon, Sindiplozoon)); and of the three suborders: (Discocotylinea, (Microcotylinea, Gastrocotylinea)). These intergeneric relationships were also supported by the skewness and principal component analyses.

(Continued on next page)
\end{abstract}

\footnotetext{
* Correspondence: gtwang@ihb.ac.cn

${ }^{1}$ Key Laboratory of Aquaculture Disease Control, Ministry of Agriculture, and

State Key Laboratory of Freshwater Ecology and Biotechnology, Institute of

Hydrobiology, Chinese Academy of Sciences, Wuhan 430072, People's

Republic of China

Full list of author information is available at the end of the article
}

(c) The Author(s). 2018 Open Access This article is distributed under the terms of the Creative Commons Attribution 4.0 International License (http://creativecommons.org/licenses/by/4.0/), which permits unrestricted use, distribution, and reproduction in any medium, provided you give appropriate credit to the original author(s) and the source, provide a link to the Creative Commons license, and indicate if changes were made. The Creative Commons Public Domain Dedication waiver (http://creativecommons.org/publicdomain/zero/1.0/) applies to the data made available in this article, unless otherwise stated. 


\begin{abstract}
(Continued from previous page)
Conclusions: Our results show that nad2, atp6 and nad6 (fast-evolving) would be better candidates than cox1 (slow-evolving) for species identification and population genetics studies in Diplozoidae. Nucleotide bias and codon and amino acid usage patterns of the three diplozoid mitogenomes are more similar to cestodes and trematodes than to other monogenean flatworms. This unusual mutational bias was reflected in disproportionately long branches in the phylogram. Our study offsets the scarcity of molecular data for the subclass Polyopisthocotylea to some extent, and might provide important new insights into the evolutionary history of the three genera and three suborders.
\end{abstract}

Keywords: Phylogenomics, Mutational bias, Molecular marker, Long branch, Amino acid usage, Ancestral gene order reconstruction

\section{Background}

As an adaptation to a broad range of dramatically different environments, monogenean flatworms often exhibit unique and exciting (from scientific perspective) life history strategies [1]. Monogeneans belonging to the Diplozoidae family are ectoparasitic on the gills of (mainly) freshwater cyprinid and characid fishes [2]. Like all monogeneans, these parasites have a direct life-cycle (no intermediate host), but all species (approximately 60) [3] in this family are characterized by their unique life-history, where two larvae (diporpae) permanently fuse into a pair, morphing into an X-shaped single organism [4,5]. Although this feature makes them very interesting from the broader perspective of evolutionary biology, they mostly received scientific attention for the damage they cause to their hosts: the pair of central hooks and four pairs of clamps which they use to attach themselves onto the gills of host [6] causes mechanical damage to the gill filaments, which often results in secondary infections (bacterial, mycotic) and anemia $[7,8]$.

Taxonomy and phylogeny of diplozoids are mainly based on morphology (central hooks, clamps and spermatozoid ultrastructure), host fishes, and single molecular marker (usually ITS2) data [3, 6, 9-14]. Nevertheless, there are several limitations to these methods. As discussed in our recent paper [15], morphological traits are liable to exhibit homoplasy in (parasitic) microscopic animals, causing taxonomic and phylogenetic artifacts. Furthermore, morphological characters of phylogenetic importance for diplozoids (central hooks, clamps) develop gradually in different developmental stages [11]. Host-specificity also played an important role in previous diplozoid classification studies [11]. Although monogeneans are considered to be highly host-specific parasites [16], species belonging to the Diplozoidae family exhibit unusual heterogeneity in terms of host specificity $[9,17]$. As a result of this host plasticity, wrong taxonomic conclusions are often reached when arbitrarily describing a diplozoid species using solely the criterion of host species. Examples of such artefacts are six Chinese Paradiplozoon species and two Inustiatus species, all of which parasitise on different hosts, but exhibit negligible interspecific genetic differentiation, which indicates that they are most likely conspecifics $[3,9,12,18]$.

Regarding the molecular markers traditionally used to infer the phylogeny of Diplozoidae, studies mostly relied on nucleotide sequence of the second internal transcribed spacer of ribosomal DNA (ITS-2 rDNA) [9, 11-14, 17, 19]. However, many of these studies reported that different analytical methods and datasets produce incongruent results $[9,12,13]$. As proposed for other commonly-used single molecular markers, such as 18S rRNA [20], it is highly likely that these problems were caused by the limited resolution of phylogenetic signal carried by the short (around 700 bp) ITS-2 rDNA sequence. This suggests that molecular markers that carry the amount of information sufficient to provide a much higher resolving power would have to be employed by future studies $[20,21]$. Mitogenomes appear as a good candidate, as they can provide a phylogenetic resolution superior to the traditionally used molecular markers, and thus have been widely used to infer the phylogenetic relationships of metazoan lineages [22-24]. Apart from contributing genetic data for phylogenetic studies, the availability of mitochondrial genomes is also a prerequisite for metaanalyses aimed at decoding the mechanisms of genomic evolution [22, 25].

Metazoan mitochondrial genomes possess numerous characteristics that make them suitable for phylogenetic studies: abundance of mitochondria in animal tissues, maternal inheritance, absence of introns, small size of genomes, and a rapidly growing number of complete mitogenomes deposited in public databases [26, 27]. Simultaneously, mitogenomes have become an increasingly popular tool in population genetics [28], phylogenetics [29,30] and diagnostics [21,31] of parasitic flatworms (Neodermata). However, their applicability is still somewhat curbed by the fact that many taxonomic categories remain poorly or not at all represented. Among the three major groups of neodermatans, mitogenomic sequences of the class Monogenea account for merely $16.8 \%$ of available mitogenomes [15]. Furthermore, within the underrepresented Monogenea, mitogenomes are available for only 
three species of the subclass Polyopisthocotylea (syn. Polyonchoinea, see [26]). All three mitogenomes belong to species classified into the order Mazocraeidea (Monogenea); representing two of its five suborders: Microcotylinea and Gastrocotylinea. Relationships among the three monogenean suborders, the aforementioned two and Discocotylinea, are controversial [32, 33]. To supplement the sparse available mitogenomic material for the subclass Polyopisthocotylea and attempt to investigate the previously described internal phylogenetic controversies, we have sequenced and characterized the mitogenomes of three species belonging to three different genera of the Diplozoidae family (Discocotylinea suborder, Mazocraeidea order). Following this, we conducted a phylogenetic analysis using the three new mitogenomes and all 18 monogenean mitogenomes available in the GenBank. The aim of the phylogenetic analysis was to: (1) explore the debated intergeneric relationships of the family Diplozoidae; and (2) explore the debated relationships of the three Mazocraeidea suborders: Discocotylinea, Microcotylinea and Gastrocotylinea.

\section{Results}

\section{Genome organization and base composition}

The full circular mitochondrial genomes of Eudiplozoon sp. and Sindiplozoon sp. are 14,334 bp and 15,254 bp in size (GenBank accession numbers are MG458328 and MG458326, respectively). The partial mitogenome of Paradiplozoon opsariichthydis Jiang, Wu \& Wang, 1984 is 15,385 bp long (GenBank accession number MG458327). All of the typical 36 flatworm mitochondrial genes [23] were found in the three genomes, including twelve proteinencoding genes (PCGs), 22 tRNA genes, two rRNA genes (Additional file 1). All three mitogenomes lack the atp 8 gene, and all genes are transcribed from the same strand. The architecture, gene contents and similarity of orthologous sequences for the three studied mitogenomes are summarized in Table 1 . Noteworthy, G + T content, as well as the degree of GC- and AT-skews, of the whole genome (and its individual elements) in all three studied species were higher than in other monogeneans (Fig. 1g).

\section{Protein-coding genes and codon usage}

Concatenated PCGs were 10,284, 10,389 and 10,326 bp in size, with $\mathrm{A}+\mathrm{T}$ contents of $70.7 \%, 67.5 \%$ and $68 \%$, for Eudiplozoon sp., P. opsariichthydis and Sindiplozoon sp. respectively. Third codon position exhibited the highest $\mathrm{A}+\mathrm{T}$ bias (Additional file 2). Commonly used ATG and GTG initial codons were found in most of the PCGs of the three studied mitogenomes. However, it proved difficult to determine the start codons of several genes for the three species. As a working hypothesis, we proposed some presumptive initial codons based on the alignment with orthologs of other monogeneans: TTG for nad5 in Eudiplozoon sp., ATT for atp 6 and nad2 in P. opsariichthydis, and GTT (nad3) and TTG (nad1, cytb, nad2 and cox1) in Sindiplozoon sp.. Most of the PCGs used the canonical TAA (includes the abbreviated T-- form) and TAG as stop codons (Table 1). Codon usage, RSCU, and codon family (corresponding to the amino acids) proportions were investigated among the six available polyopisthocotylid representatives (3 new +3 old, Additional file 3). In comparison to other monogeneans, diplozoids exhibit a strong preference for amino acids encoded by guanine and thymine-rich codon families (such as Phe, Val and Gly), whereas amino acids encoded by adenosine and cytosine-rich codon families (such as Asn and Thr) appear to be selected against (Fig. 2 and Additional file 3). Principal component analyses (PCA) suggested that the overall codon usage of all three diplozoids and amino acid usage patterns of $P$. opsariichthydis and Sindiplozoon sp. were notably different from other monogeneans (Fig. 1e and f). Instead, they were more similar to trematodes and cestodes, in accordance with the results of nucleotide skewness (Fig. 1a-d). Within the Diplozoidae, the codon usage pattern of Sindiplozoon sp. was similar to that of P. opsariichthydis (Fig. 1e and f), which is also congruent with the results of nucleotide composition and skewness.

\section{Transfer RNA genes}

All 22 standard tRNAs were found (Table 1, Figs. 3 and 4), and most of them could be folded into the conventional cloverleaf structure (Figs. 3 and 4). Exceptions were $\operatorname{trnS1} 1^{(\mathrm{AGN})}$ and $\operatorname{trnS2} 2^{(\mathrm{UCN})}$, which lacked DHU arms (Figs. 3 and 4). The first site of anticodon sequences of all tRNAs was $\mathrm{T}$ or G, except for $\operatorname{trn} M$ and $\operatorname{trnK}$ in all three studied mitogenomes, and trnR in Eudiplozoon sp. and Sindiplozoon sp. (Figs. 3 and 4). The percentage of identical nucleotides among tRNA orthologs of the three mitogenomes (all three compared simultaneously) ranged from $40(\operatorname{trnK})$ to 65 (trnP) (Additional file 4), which partially corresponds to the average identities of orthologous sequences (Table 1). Nucleotide substitutions observed among the tRNAs of the three diplozoid mitogenomes are mainly restricted to the TYC and DHU loops, whereas the anticodon loop is highly conserved (Figs. 3 and 4). We also found a number of nucleotide substitutions in three different stems (acceptor, anticodon and $\mathrm{T} \Psi \mathrm{C}$ ), but most of them are compensatory base changes occurring in both paired nucleotides (cbc; i.e., G-C $\leftrightarrow$ A-T) and/or hemi-cbcs (a mutation of a single nucleotide in a pair, while maintaining the nucleotide bond, e.g. G-T $\leftrightarrow$ A-T) (Figs. 3 and 4). However, the DHU stem was extremely conserved, with only two cbcs, seven hemi-cbcs, one reverse change (i.e., A-T $\leftrightarrow$ T-A) and one mismatched pair (T-T) among all 22 tRNAs (Figs. 3 and 4). Additionally, unmatched base insertions were observed in the stems of two tRNAs: there is an unmatched $\mathrm{T}$ base 
Table 1 Comparison of the annotated mitochondrial genomes of Paradiplozoon opsariichthydis, Sindiplozoon sp. and Eudiplozoon sp.

\begin{tabular}{|c|c|c|c|c|c|c|c|}
\hline \multirow[t]{2}{*}{ Gene } & \multicolumn{2}{|l|}{ Position } & \multirow[t]{2}{*}{ Size } & \multicolumn{2}{|l|}{ Codon } & \multirow[t]{2}{*}{ Anti-codon } & \multirow[t]{2}{*}{ Identity } \\
\hline & From & To & & Start & Stop & & \\
\hline \multicolumn{7}{|c|}{ Eudiplozoon sp. / Paradiplozoon opsariichthydis / Sindiplozoon sp. } & ES-PO/ES-SS/PO-SS/A \\
\hline $\operatorname{cox} 3$ & $1 / 1 / 1$ & 756/780/762 & $756 / 780 / 762$ & ATG/ATG/ATG & TAA/TAG/TA & & $60.13 / 56.49 / 53.91 / 56.85$ \\
\hline $\operatorname{trn} C$ & $755 / 763 / 821$ & 819/822/888 & $65 / 60 / 68$ & & & GCA/GCA/GCA & $56.92 / 76.47 / 63.24 / 65.54$ \\
\hline trnk & $826 / 826 / 897$ & $894 / 890 / 961$ & $69 / 65 / 65$ & & & CTT/CTT/CTT & $55.71 / 53.52 / 69.70 / 59.64$ \\
\hline nad6 & $1481 / 2320 / 2167$ & $1931 / 2796 / 2643$ & $451 / 477 / 477$ & GTG/ATG/GTG & T/TAA/TAG & & $52.41 / 57.29 / 52.85 / 54.18$ \\
\hline $\operatorname{trn} Y$ & 1941/2776/2673 & 2003/2844/2738 & 63/69/66 & & & GTA/GTA/GTA & $59.42 / 71.21 / 68.12 / 66.25$ \\
\hline $\operatorname{trnL1}$ & 2004/2857/2766 & 2071/2923/2829 & $68 / 67 / 64$ & & & $\mathrm{TAG} / \mathrm{TAG} / \mathrm{TAG}$ & $54.93 / 55.07 / 62.69 / 57.56$ \\
\hline $\operatorname{trnS2}$ & 2076/2926/2838 & $2136 / 2985 / 2896$ & $61 / 60 / 59$ & & & TGA/TGA/TGA & $65.57 / 68.85 / 66.67 / 67.03$ \\
\hline $\operatorname{trn} L 2$ & 2137/2986/2900 & $2205 / 3052 / 2964$ & $69 / 67 / 65$ & & & TAA/TAA/TAA & $70.42 / 69.57 / 65.67 / 68.55$ \\
\hline $\operatorname{trn} R$ & 2207/3053/2966 & 2270/3116/3027 & $64 / 64 / 62$ & & & ACG/TCG/ACG & 68.75/75.00/67.19/70.31 \\
\hline nad5 & $2271 / 3118 / 3002$ & $3821 / 4657 / 4559$ & $1551 / 1540 / 1558$ & TTG/ATG/GTG & $\mathrm{TAG} / \mathrm{T} / \mathrm{T}$ & & $54.54 / 61.90 / 55.63 / 57.35$ \\
\hline $\operatorname{trn} E$ & $3802 / 4658 / 4560$ & $3868 / 4721 / 4626$ & $67 / 64 / 67$ & & & ТTC/TTC/TTC & $39.47 / 69.57 / 52.24 / 53.76$ \\
\hline cytb & $3871 / 4722 / 4628$ & $5016 / 5885 / 5803$ & $1146 / 1164 / 1176$ & GTG/ATG/TTG & TAG/TAA/TAC & & 63.20/65.56/65.17/64.64 \\
\hline $\operatorname{nad} 4 \mathrm{~L}$ & $5022 / 5876 / 5784$ & $5279 / 6142 / 6059$ & 258/267/276 & GTG/ATG/GTG & $\mathrm{TAG} / \mathrm{TAG} / \mathrm{TAC}$ & & $62.17 / 55.43 / 55.67 / 57.76$ \\
\hline nad4 & $5243 / 6152 / 6011$ & $6484 / 7408 / 7261$ & $1242 / 1257 / 1251$ & ATG/ATG/GTG & $\mathrm{TAG} / \mathrm{TAG} / \mathrm{TAC}$ & & $61.45 / 62.78 / 60.84 / 61.69$ \\
\hline $\operatorname{trnF}$ & 6493/7526/7390 & 6558/7591/7456 & $66 / 66 / 67$ & & & GAA/GAA/GAA & 78.79/58.21/55.22/64.07 \\
\hline $\operatorname{trn} Q$ & $6622 / 7606 / 7474$ & $6683 / 7667 / 7535$ & $62 / 62 / 62$ & & & ITG/TTG/TTG & $58.06 / 66.13 / 59.68 / 61.29$ \\
\hline atp6 & 6696/7676/7565 & 7277/8293/8140 & $582 / 618 / 576$ & GTG/ATT/ATG & TAA/TAA/TAC & & 49.84/55.56/53.55/52.98 \\
\hline nad2 & 7286/8339/8146 & $8161 / 9217 / 9033$ & 876/879/888 & ATG/ATT/TTG & $\mathrm{TAG} / \mathrm{TAG} / \mathrm{TAC}$ & & $53.96 / 55.64 / 56.67 / 55.42$ \\
\hline $\operatorname{trnV}$ & $8163 / 9218 / 9045$ & $8226 / 9281 / 9111$ & $64 / 64 / 67$ & & & TAC/TAC/TAC & $50.00 / 64.18 / 60.87 / 58.35$ \\
\hline $\operatorname{trn} A$ & $8236 / 9282 / 9128$ & $8300 / 9342 / 9191$ & $65 / 61 / 64$ & & & TGC/TGC/TGC & $56.92 / 72.31 / 64.06 / 64.43$ \\
\hline $\operatorname{trn} D$ & 8303/9344/9195 & $8368 / 9405 / 9263$ & $66 / 62 / 69$ & & & GTC/GTC/GTC & 60.61/52.11/62.32/58.35 \\
\hline nad1 & $8371 / 9407 / 9264$ & $9294 / 10315 / 10185$ & 924/909/922 & ATG/ATG/TTG & $\mathrm{TAG} / \mathrm{TAG} / \mathrm{T}$ & & 63.69/68.17/65.30/65.72 \\
\hline $\operatorname{trn} N$ & 9294/10320/10194 & $9358 / 10383 / 10256$ & $65 / 64 / 63$ & & & GTT/GTT/GTT & 61.19/68.18/62.50/63.96 \\
\hline $\operatorname{trn} P$ & $9360 / 10388 / 10266$ & $9423 / 10449 / 10327$ & $64 / 62 / 62$ & & & $\mathrm{TGG} / \mathrm{TGG} / \mathrm{TGG}$ & $78.12 / 76.92 / 75.00 / 76.68$ \\
\hline $\operatorname{trnl}$ & $9428 / 10451 / 10342$ & $9495 / 10517 / 10410$ & $68 / 67 / 69$ & & & GAT/GAT/GAT & $82.35 / 73.91 / 62.32 / 72.86$ \\
\hline nad3 & $9498 / 10521 / 10420$ & $9794 / 10784 / 10698$ & 297/264/279 & ATG/ATG/GTT & TAA/TAA $/ A C$ & & $56.25 / 64.00 / 56.89 / 59.05$ \\
\hline $\operatorname{trnS1}$ & 9802/10803/10701 & $9865 / 10870 / 10759$ & $64 / 68 / 59$ & & & GCT/GCT/GCT & 60.87/67.19/64.71/64.25 \\
\hline $\operatorname{trn} W$ & $9867 / 10871 / 10760$ & $9930 / 10935 / 10825$ & $64 / 65 / 66$ & & & TCA/TCA/TCA & $72.73 / 57.58 / 75.76 / 68.69$ \\
\hline $\operatorname{cox} 1$ & $9940 / 10939 / 10827$ & $11,511 / 12546 / 12399$ & 1572/1608/1573 & ATG/ATG/TTG & TAA/TAG/T & & 71.02/75.00/70.91/72.31 \\
\hline $\operatorname{trn} G$ & $11,518 / 7417 / 12409$ & $11,582 / 7479 / 12475$ & $65 / 63 / 67$ & & & ТСС/TCC/TCC & 62.12/71.64/67.16/66.98 \\
\hline $\operatorname{trn} T$ & $11,786 / 12873 / 12673$ & $11,852 / 12933 / 12737$ & $67 / 61 / 65$ & & & TGT/TGT/TGT & $61.19 / 70.15 / 72.31 / 67.88$ \\
\hline$r r n L$ & $11,853 / 12934 / 12740$ & $12,826 / 13898 / 13718$ & 974/965/979 & & & & 73.98/78.34/73.96/75.43 \\
\hline$r r n S$ & 12,827/13899/13719 & $13,555 / 14633 / 14448$ & 729/735/730 & & & & 68.59/73.96/70.07/70.87 \\
\hline $\cos 2$ & $13,556 / 14634 / 14487$ & $14,185 / 15260 / 15077$ & 630/627/591 & ATG/ATG/ATG & $\mathrm{TAG} / \mathrm{TAG} / \mathrm{TAC}$ & & $58.57 / 65.40 / 58.05 / 60.67$ \\
\hline $\operatorname{trn} M$ & $14,190 / 15259 / 15116$ & $14,254 / 15322 / 15181$ & $65 / 64 / 66$ & & & САT/CAT/CAT & $65.67 / 85.07 / 60.61 / 70.45$ \\
\hline $\operatorname{trnH}$ & $14,269 / 15323 / 15187$ & $14,334 / 15383 / 15251$ & $66 / 61 / 65$ & & & GTG/GTG/GTG & $57.58 / 74.63 / 58.46 / 63.55$ \\
\hline
\end{tabular}

ES Eudiplozoon sp., PO Paradiplozoon opsariichthydis, SS Sindiplozoon sp., $A$ average identity values (\%) of the three diplozoids

inserted in the anticodon stem of $\operatorname{trn} H$, autapomorphic for Sindiplozoon sp., and an unmatched A base in the acceptor stem of trnI, which appears to be synapomorphic for diplozoids, and possibly even monogeneans (Fig. 3).

\section{Non-coding regions}

All three studied mitogenomes, Eudiplozoon sp., $P$. opsariichthydis and Sindiplozoon sp., contain two large non-coding regions: a long non-coding region (LNR; 586, 


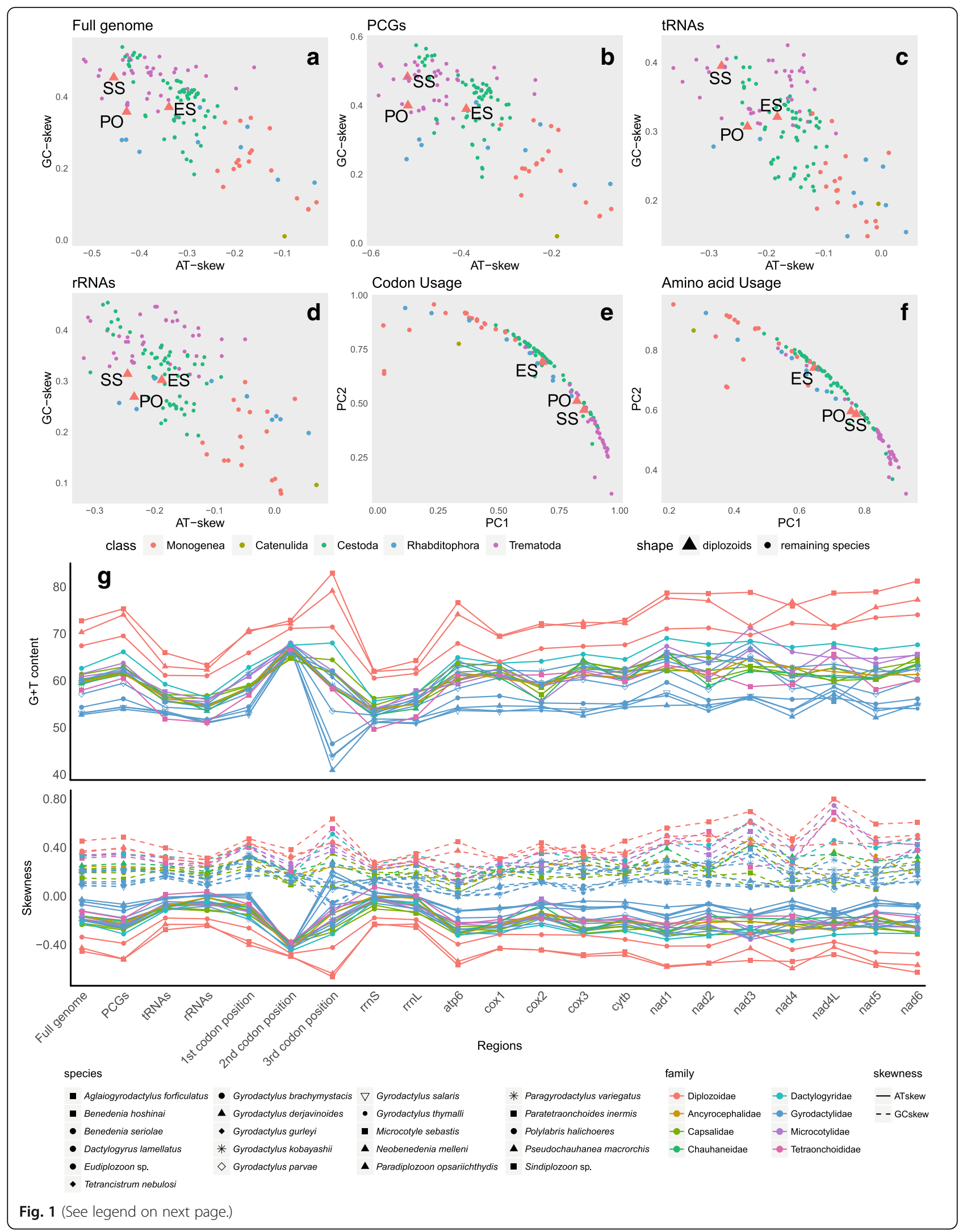


(See figure on previous page.)

Fig. 1 Nucleotide skews, codon usage, amino acid usage, and G + T content of the three studied mitogenomes, and comparison with other flatworms. a-d Comparison of nucleotide skews of the full genomes, protein-coding genes (PCGs), tRNAs and rRNAs for the mitogenomes of Paradiplozoon opsariichthydis, Sindiplozoon sp. and Eudiplozoon sp., and other flatworms. e, $\mathbf{f}$ Principal component (PC) analysis of the codon usage and amino acid usage in the PCGs of the three studied diplozoids and other flatworms. The first PC (PC1) and the second PC (PC2) of the codon usage and amino acid usage accounted for $95.8 \%$ and $94.7 \%$ of the variability, respectively. $\mathbf{g} \mathrm{G}+\mathrm{T}$ content and skewness of complete genomes and their individual elements. Species are colored according to their taxonomic placement at the class level in figure panels a-f and family level in the panel g. The three studied diplozoids are represented by triangles. ES: Eudiplozoon sp.; PO: Paradiplozoon opsariichthydis; SS: sindiplozoon sp.

1429 and 1205 bp respectively; note that the LNR of $P$. opsariichthydis is incomplete) and a short non-coding region (SNR; 203, 326 and 197 bp respectively). LNR and SNR of the three species are located between $\operatorname{trn} K$ and $n a d 6$, and $\operatorname{trn} G$ and trnT, respectively. Beyond this, there is an extra SNR (SNR1) in the mitogenome of Sindiplozoon sp.; 128 bp in size and located between trnF and nad4L. Tandem repeats (TRs) could not be found in any of the SNRs (including the SNR1 of Sindiplozoon sp.), but putative secondary structures containing a stem-loop were found in all of these sequences (Additional file 5). Several TR elements were predicted in LNRs of the three studied mitogenomes. A short TR region, composed of seven TRs, was found in the LNR of Sindiplozoon sp. Lengths and nucleotide composition of these seven repeat units were not highly conserved, but all were rich in $\mathrm{A}+\mathrm{T}$ (Additional file 5). Within the LNR of P. opsariichthydis there was a large TR region (Additional file 5). Additionally, we found

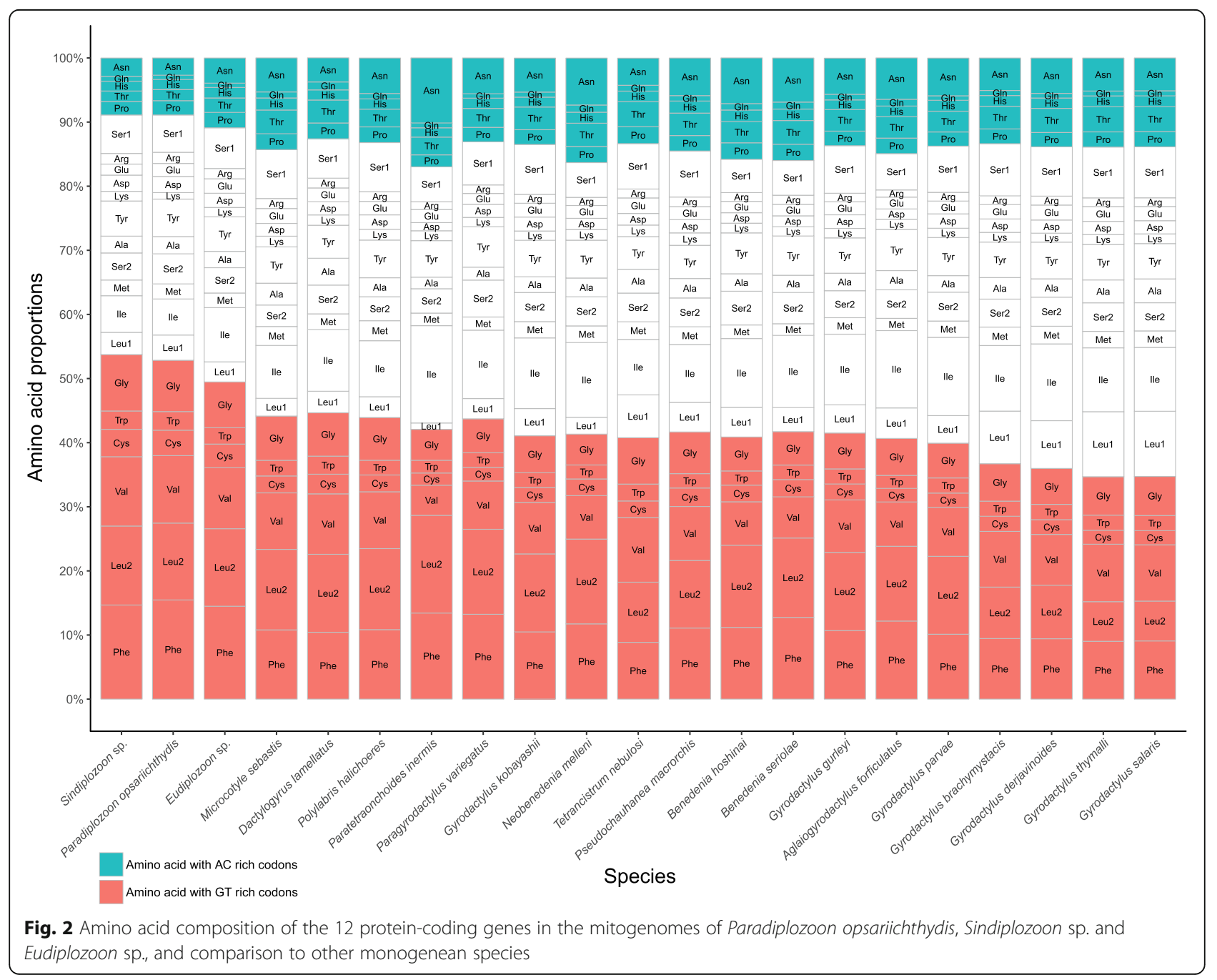



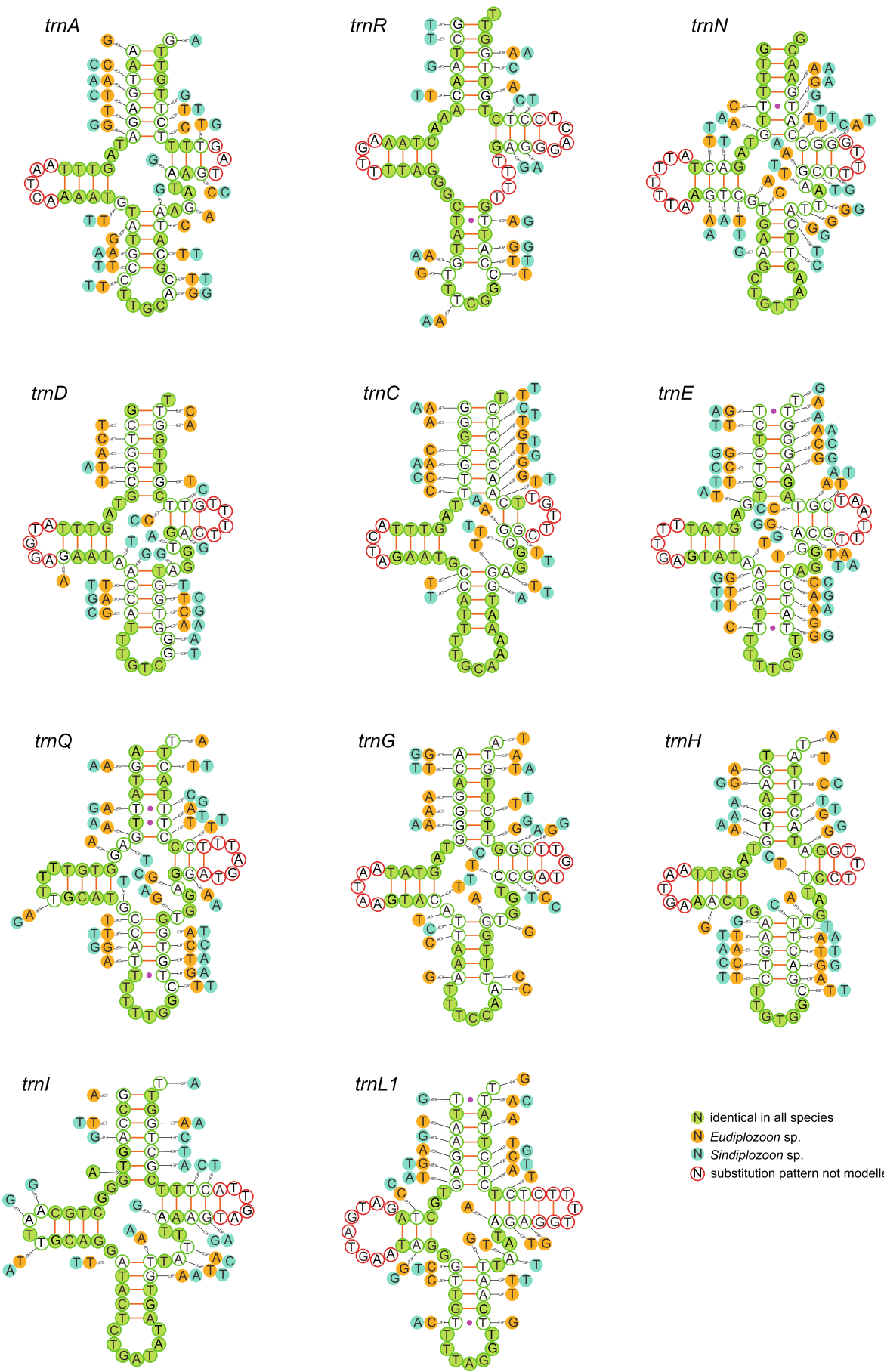

$\mathrm{N}$ identical in all species

N Eudiplozoon sp.

N Sindiplozoon $\mathrm{sp}$

(N) substitution pattern not modelled

Fig. 3 Secondary structures of tRNA families (trnA-trnL1) in diplozoid mitogenomes. Nucleotide substitution pattern for each tRNA family was modeled against the reference structure determined for Paradiplozoon opsariichthydis. Arrows in $\operatorname{trnH}$ and $\operatorname{trn} /$ denote a nucleotide insertion and an unmatched nucleotide in the acceptor stem

microsatellite-like elements in all three LNRs: $\mathrm{TA}_{22}$ in Eudiplozoon sp., $\mathrm{TA}_{64}$ (with four nucleotide mutations, one $\mathrm{G}$ insertion and one $\mathrm{T} / \mathrm{A}$ position exchange) in P. opsariichthydis, and $\mathrm{TA}_{20}$ (with two mutations) in Sindiplozoon sp..
Sliding window analysis and nucleotide diversity

The sliding window analysis was conducted using the alignment of entire mitogenomes of the three studied diplozoids (trnG was removed from this analysis due to its position rearrangement). The plot of sequence variation 

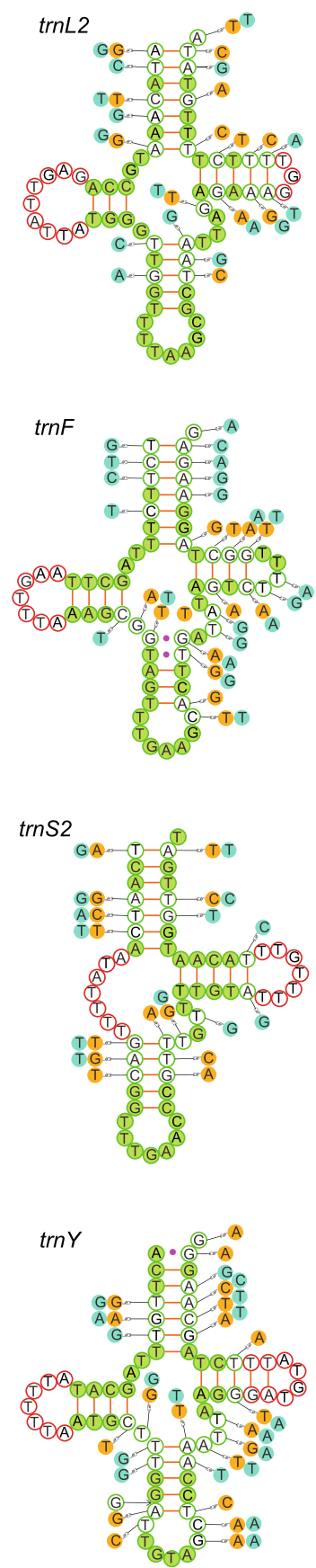
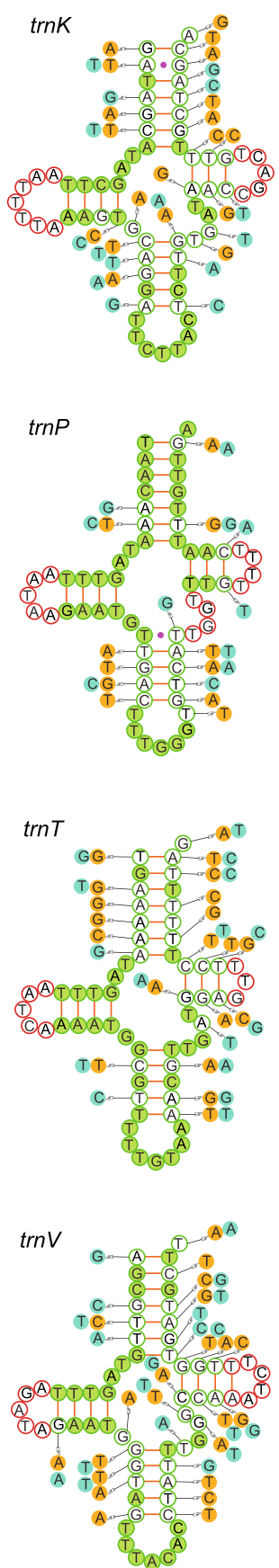
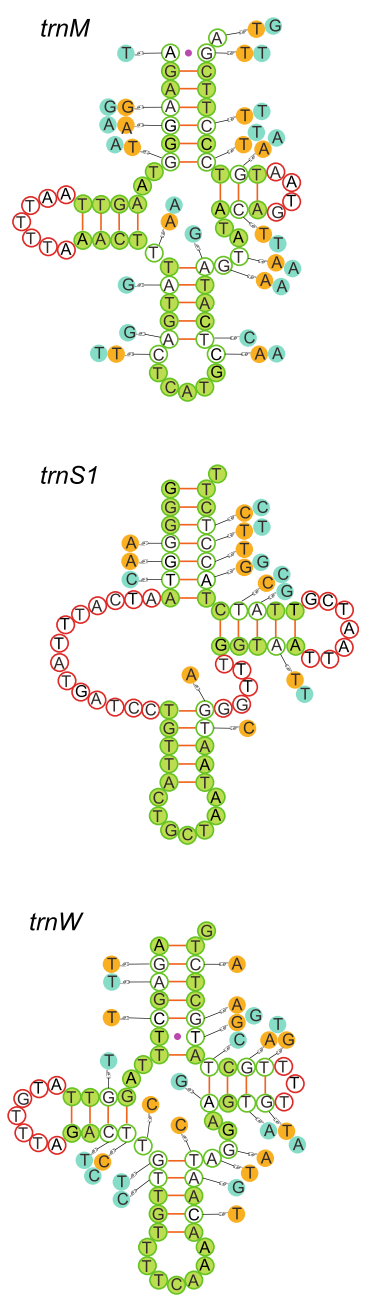

N identical in all species

N Eudiplozoon sp.

(N) substitution pattern not modelled

Fig. 4 Secondary structures of tRNA families (trnL2-trnV) in diplozoid mitogenomes. Nucleotide substitution patterns were modeled against the reference structure determined for Paradiplozoon opsariichthydis

ratio exhibited highly variable nucleotide diversity among the three aligned mitogenomic sequences, with $\mathrm{Pi}$ values for the $200 \mathrm{bp}$ windows ranging from 0.12 to 0.485 (Fig. 5a). Genes with comparatively low sequence variability included cox1 (0.265), rrnL (0.236), rrnS (0.269), nad1 (0.328) and cytb (0.339), while genes with comparatively high sequence variability included nad2 (0.443), atp6 (0.439), nad6 (0.422), nad4L (0.417) and nad5 (0.41). These observations were also reflected in the results of $d N / d S$ ratio (Fig. $5 b$ ) and average sequence identity (Table 1) analyses. However, similarity values strongly varied among different fragments of most genes (Fig. 5a).

\section{Phylogeny and gene order}

Both ML analysis and BI analyses with MTART and CAT+ MTART models produced phylograms with concordant 


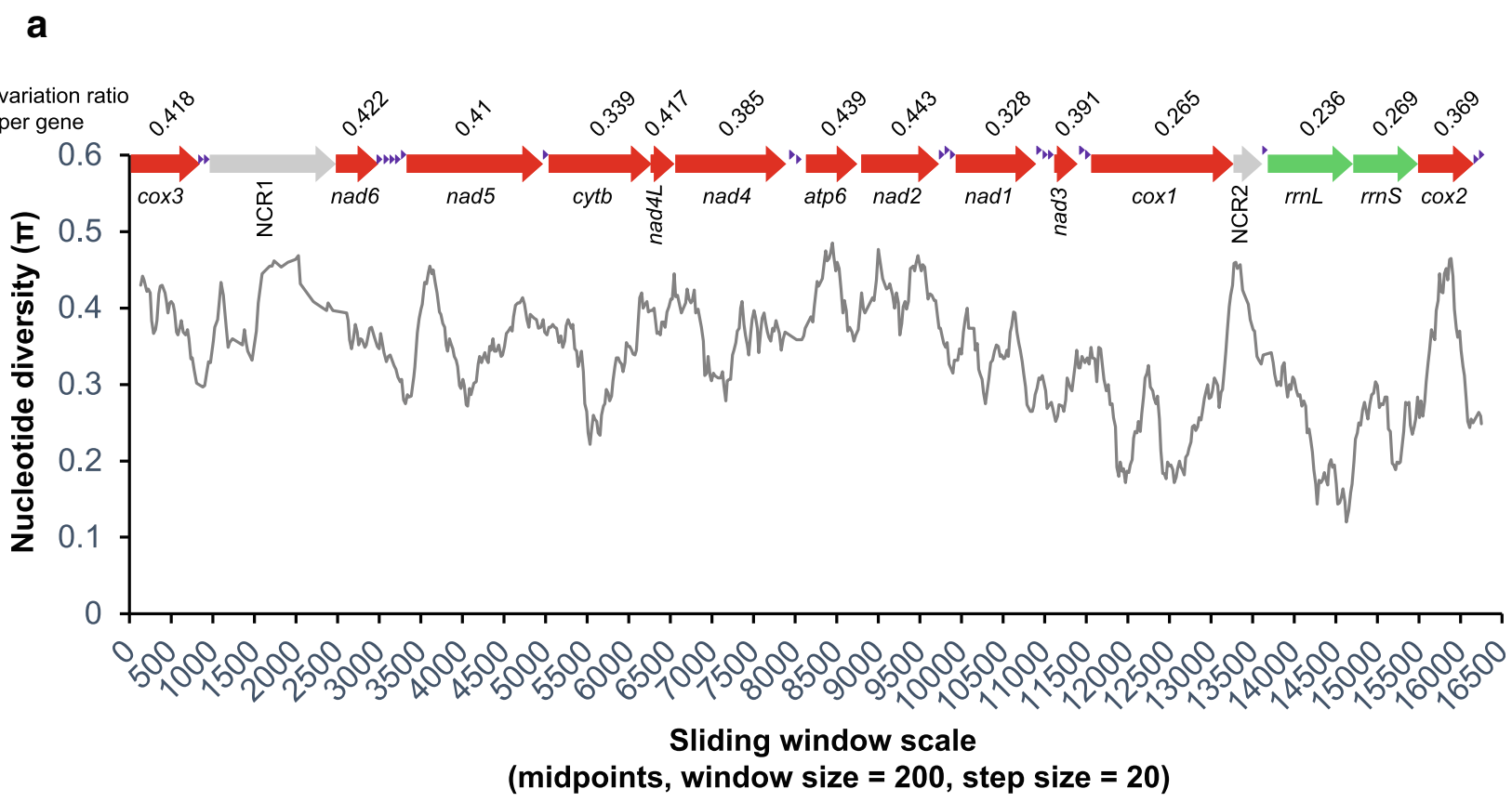

b Eudiplozoon sp.-Paradiplozoon opsariichthydis $\quad$ Eudiplozoon sp.-Sindiplozoon sp. $\quad$ Paradiplozoon opsariichthydis-Sindiplozoon sp.

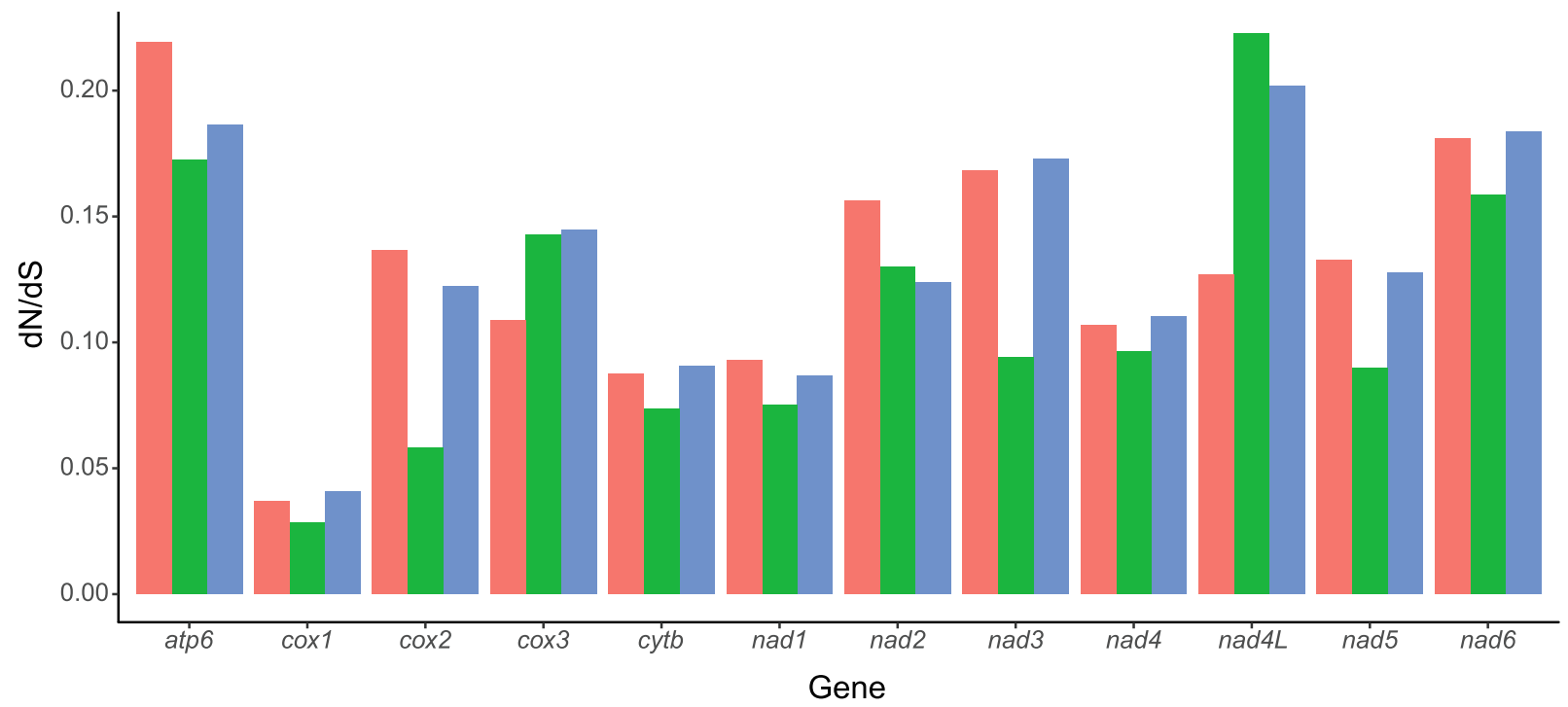

Fig. 5 Selection pressures and sliding window analyses of the three diplozoid mitogenomes. a Sliding window analysis of the alignment of complete mtDNAs of the three diplozoids. trnG was removed from the analysis due to its position change. The black line represents the value of nucleotide diversity in a sliding window analysis (window size $=200 \mathrm{bp}$, step size $=20 \mathrm{bp}$, with the value inserted at its mid-point). Gene boundaries are indicated with a variation ratio per gene (above each gene). b Ratios of non-synonymous (dN) to synonymous (dS) substitution rates calculated from individual protein-coding genes of Paradiplozoon opsariichthydis, Sindiplozoon sp. and Eudiplozoon sp.

branch topologies (Fig. 6). The Polyopisthocotylea clade was sub-divided into two clades, (Chauhaneidae+Microcotylidae) and Diplozoidae, both robustly supported (Bayesian posterior probabilities $=0.9$ and 1 , respectively, Fig. 6). As expected, the three diplozoids, Eudiplozoon sp., P. opsariichthydis and Sindiplozoon sp., constituted a monophyletic group with high support. The LG model, however, produced a different topology, with paraphyletic Diplozoidae (Additional file 6).

The gene orders of Eudiplozoon sp. and Sindiplozoon sp. were identical, while $P$. opsariichthydis exhibited a relocation of $\operatorname{trn} G$ to the position between nad4 and trnF. Ancestral gene order reconstruction using both CREx and MLGO based on the optimal topology (the 


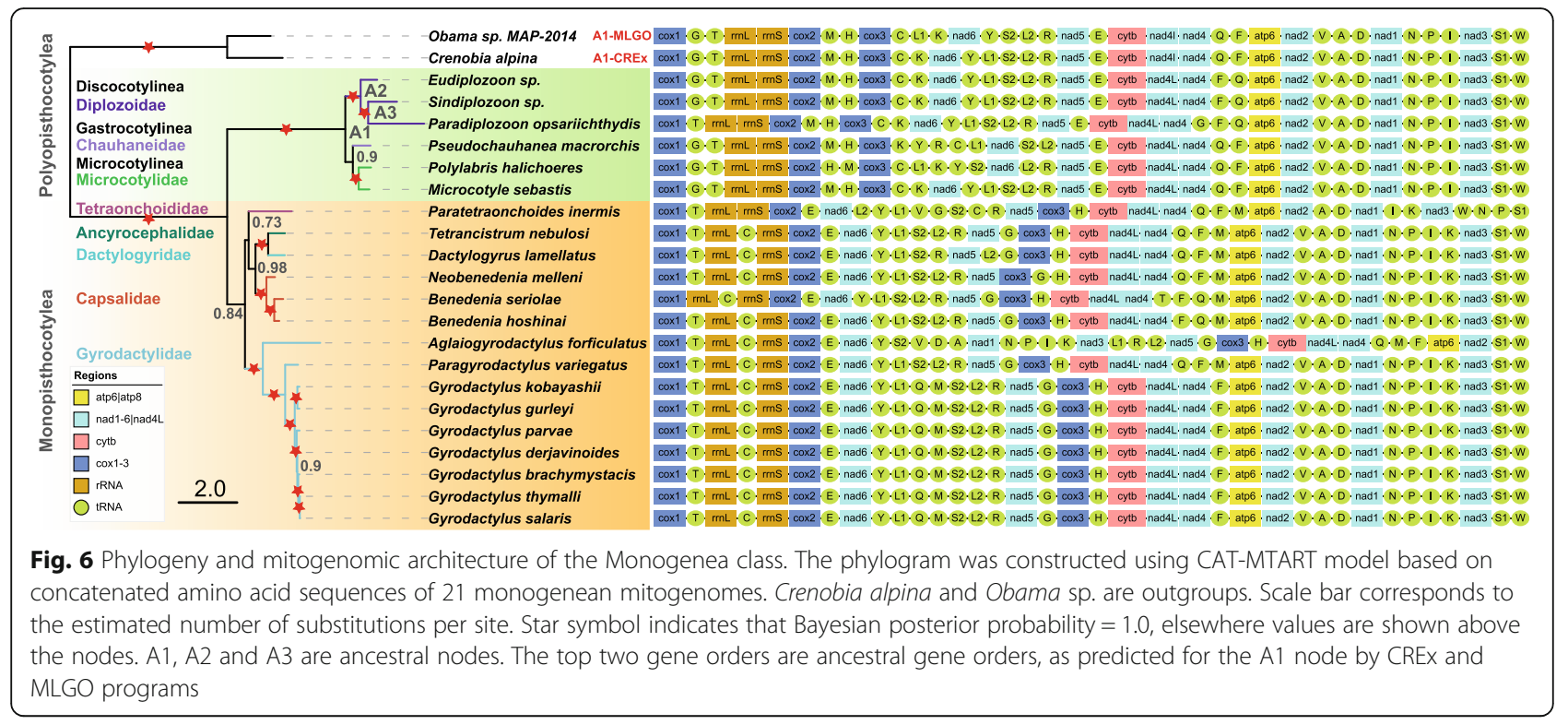

one generated by the MTART model) showed that the gene order as exhibited by Eudiplozoon sp. and Sindiplozoon sp. represents the ancestral state for the Diplozoidae family (i.e., the gene orders of A2 and A3 nodes are identical to these two species, Fig. 6). However, albeit the difference was minor (the position of trnL1), the two algorithms (CREx and MLGO) produced two different ancestral gene orders for the subclass Polyopisthocotylea. MLGO proposed the -trnY-trnL1-trnS2order and CREx proposed the -trnC-trnL1-trnK- order (Fig. 6).

\section{Discussion}

\section{Specimen identity}

Identification of all three specimens was somewhat problematic, which additionally emphasizes the pressing need for a larger number of mitogenomes to be available in public databases. To support our morphological identification, we have provided high-resolution microscopic photographs of taxonomically important morphological traits (central hooks and clamps) for all three diplozoids (Additional files 7, 8 and 9). Both morphology (Additional file 7) and molecular data consistently identified the parasite collected from the hooksnout carp (Opsariichthys bidens) as a Paradiplozoon species. As the species in this genus are traditionally identified by their host [34], we identified it as $P$. opsariichthydis. However, as shown before [9], and visible in our ITS-2 rDNA analysis (Additional file 10), the status of these six Chinese Paradiplozoon species is highly doubtful. ITS-2 data strongly indicate that there is no evidence for the existence of host-specific species: the identity between our sequence and P. opsariichthydis, P. parabramisi Ling, 1973 and P. hemiculteri Ling, 1973 orthologs is 100\% (GenBank numbers are shown in the Additional file 10).
Eudiplozoon sp. was morphologically similar to E. nipponicum (Additional file 8 ), the only recognized species in the genus, and it clustered with the six available $E$. nipponicum ITS-2 rDNA sequences (Additional file 10). Although this, as well as its host species and the locality where it was collected, indicates that it is indeed an $E$. nipponicum specimen, the ITS-2 rDNA sequence identities between our specimen and the remaining six E. nipponicum sequences were relatively low: $94 \%$ to $95 \%$. This was also reflected in the topology of the phylogram, where our sequence was basal to the otherwise homogenous $E$. nipponicum clade (Additional file 10). In addition, the comparison with the only available E. nipponicum cox 1 sequence (AY009163) indicated an even lower identity value of $83 \%$. Therefore, we suspect a possibility of the existence of a cryptic Eudiplozoon species. Further investigations of the Eudiplozoon population in Tangxun Lake are needed to establish whether the unusually low identities of ITS-2 and $\operatorname{cox} 1$ sequences are a reflection of the existence of a cryptic species, as intrahost or sympatric speciation is more likely in monogeneans than in other parasitic groups [35-37], or merely an unusually high mutational rate of genomes (both nuclear and mitochondrial) of some sub-populations.

Host-specificity of the Sindiplozoon sp. specimens was very low; we found them in Parabramis pekinensis, Spinibarbus hollandi and black carp, so host information is not particularly relevant for the identification of this species. Morphological analysis (Additional file 9) suggests the highest similarity to $S$. ctenopharyngodonis among the six valid Sindiplozoon species [34]. However, the ITS-2 rDNA sequence identity between the studied species and S. ctenopharyngodonis (the only available sequence for the entire genus in the GenBank) was $97 \%$. As five of the six 
valid Sindiplozoon species are non-represented in the GenBank, we can merely assign the specimen with certainty to the Sindiplozoon clade, but not to a particular species.

\section{Mitogenome architecture}

We have successfully amplified the long non-coding region (LNR) of the mitogenome of $P$. opsariichthydis, so we know that the approximate size is $2000 \mathrm{bp}$, but we managed to sequence only $1429 \mathrm{bp}$. Considering that the non-sequenced gap was located near the TR region, we suspect that the sequencing of this region was likely to be hampered by such long repeat sequences; possibly by the secondary structures they form $[38,39]$. The sequenced part of the LNR of $P$. opsariichthydis was comprised of only two TRs, but the sizes of both repeat units (244 bp repeat 1,197 bp repeat 2) were the largest among the TRs reported in monogeneans so far [40-42]. A microsatellite-like TR of TA sequence (TA*) was also found in Benedenia seriolae (Yamaguti, 1934) [29]. Although the control region is generally considered to be difficult to locate in neodermatans (parasitic flatworms) [29], the presence of repeat regions is often associated with control regions $[40,43]$. As they are present in all three diplozoids, we hypothesise that the described $\mathrm{TA}^{*}$ repeat regions are most likely embedded within the control regions. The fact that two mononucleotide adenine repeats, $A_{29}$ and $\mathrm{A}_{26}$, were also detected in LNRs of Eudiplozoon sp. and Sindiplozoon sp., respectively, adds support to this hypothesis as they are also considered to be linked to the control region in fish [44].

Strong strand-specific nucleotide biases were also found in vertebrate [45] and pterobranch [46] mitogenomes. They are believed to be a consequence of strand-displacement mechanisms during the replication of mitogenomes [47]. It seems that strand-displacement modes were more prominent in cestodes and trematodes within the phylum Platyhelminthes, as they all exhibited comparatively high GC- and AT-skews (Fig. 1a-d). The three diplozoids appear to be outliers, with highest GC- and AT-skews, among the available monogenean mitogenomes (Fig. 1a-d). This finding suggests that slight GC- and AT-skews are not a synapomorphy for the class Monogenea.

Unorthodox start codons were reported in other neodermatans as well, such as ATT in B. hoshinai (Ogawa, 1984) and Aglaiogyrodactylus forficulatus (Kritsky, Vianna \& Boeger 2007) [48, 49], TTG in Paragyrodactylus variegatus (You, King, Ye \& Cone, 2014) [50] and GTT in Hymenolepis diminuta (Rudolphi, 1819) [51] (also see Additional file 11). The unusual codon frequency and the preference for $\mathrm{G}$ and/or $\mathrm{T}$ in the first site of anti-codons are a reflection of the selection for an efficient tRNA system $[46,52]$. This further confirms the wobble versatility hypothesis ( $G$ pairs with $T$ and $C, T$ pairs with $G$ and $A$ in wobble pairing) [52], which suggests that GNN is the anticodon for NNY codon, and UNN is the anticodon for NNR and NNN codons. On this basis, the anticodon sequences with highest versatility (starting with $\mathrm{G}$ or $\mathrm{T}$ ) were preferred in comparison to the anticodon sequences corresponding to the most frequent codons. In agreement with previous reports for the Nemertea phylum [53] and insects [54], our results indicate that there is no link between the abundance of codon families (Phe, Leu2 and Val are the most abundant) and the level of tRNA conservation (trnP is the most conserved) in diplozoid flatworms. Similar to gyrodactylids [55], nemerteans [53], and insects [54], some tRNAs have mismatched pairs in stems; e.g., T-T in the anticodon and acceptor stem of $\operatorname{trn} Q, \mathrm{~A}-\mathrm{G}$ in the acceptor stem of $\operatorname{trnK}$, and G-G in the anticodon stem of $\operatorname{trnF}$ (Figs. 3 and 4). They might be modified by the RNA editing process [56], or simply represent unusual pairings [57]. The high level of conservation in the DHU stem can be explained by the fact that DHU stem probably acts as a recognition site for the aminoacyl-tRNA synthetase [58]. Notably, the anticodon sequences of 21 tRNAs perfectly conformed to that of other monogeneans [15, 42, 50, 55, 59-61]. The only exception was trnR, which uses the ACG anticodon in Eudiplozoon sp. and Sindiplozoon sp., but TCG in P. opsariichthydis (Figs. 3 and 4). Although the shift of anticodon from TCG to ACG was also reported in B. hoshinai [59], this is most probably a homoplasy.

Sliding window analysis can identify regions with high nucleotide divergence, which is crucial for designing species-specific markers. These can be particularly useful in taxa where morphological identification is difficult and ambiguous, such as diplozoids. This information (variable similarity values among different fragments) can be used both for primer design and for functional studies. The $\operatorname{cox} 1$ gene is often used as an universal barcode for species identification in general [62], as well as in monogeneans [63-66]. Therefore, our results, which show that $\operatorname{cox} 1$ is the slowest evolving and least variable gene, indicate that its utility as a barcode for the family Diplozoidae, or even the entire class Monogenea, needs to be carefully tested and revised. If its resolution power indeed proves to be too low, we propose that fast-evolving nad2, atp6 or nad6 might be more suitable markers for future diagnostics/detection and population genetics studies of the family Diplozoidae.

Gene orders of the mitogenomes of Eudiplozoon sp., $P$. opsariichthydis and Sindiplozoon sp. conformed to the ground pattern of the subclass Polyopisthocotylea (pattern 3 in our recent paper [15]). Based on the ancestral gene order reconstruction results, the gene order of $P$. opsariichthydis was derived via a $\operatorname{trn} G$ transposition from the 3' end of $\operatorname{cox} 1$ to the 3 ' end of nad4, and may be autapomorphic to the genus Paradiplozoon. Additionally, a position exchange 
between $\operatorname{trn} F$ and $\operatorname{trn} Q$ appears to have occurred in the common ancestor of the Diplozoidae family, distinguishing it from the ancestral gene order of the subclass Polyopisthocotylea. We hypothesise that the ancestral gene order (-trnY-trnL1-trnS2-) predicted by MLGO is more likely to be the ancestral state, as it appears to be more common in the available monogenean mitogenomes.

\section{Phylogeny}

BI-LG and ML analyses produced incongruent topologies, with Diplozoidae resolved as paraphyletic in the former (Additional file 6). However, the paraphyly is likely to have been caused by the use of a sub-optimal $L G+I+G+F$ model, as the optimal MTART model is not available in MrBayes. Regardless, this is rather intriguing (and therefore discussed here), because in our previous study BI and ML analyses of an almost identical dataset (minus the three new diplozoids) and using evolutionary identical models (BI - LG, ML - MTART) produced identical topologies [15]. Given that the two topologies are incongruent only regarding the three diplozoids, a possible explanation for this phenomenon would be comparatively long branches of all three diplozoids, but especially $P$. opsariichthydis (Additional file 6). We presume this is a reflection of the unusual nucleotide composition and amino acid usage of these three mitogenomes. A similar artefact, high GT content and a disproportionately long branch, was also reported in the unrelated Rhabdopleura compacta (Hincks, 1880) (Hemichordata) [46]. To attempt to resolve this problem by using a better-suited evolutionary model, we employed Phylobayes to conduct BI analysis with the optimal model (MTART) and a siteheterogeneous model with empirical matrixes CAT+ MTART. Topologies produced by these two analyses are identical to the one produced by the ML analysis, which corroborates that incongruence was produced by the use of an unsuitable model LG. As this strategy, replacing the optimal MTART model with the closest model available in MrBayes, has been used in several studies [67-70], our results provide a note of caution regarding the interpretation of these results. We would encourage researchers to use PhyloBayes in such circumstances.

As the Diplozoidae + (Chauhaneidae + Microcotylidae) families belong to three different suborders, this also indicates that the suborder relationships are Discocotylinea + (Microcotylinea + Gastrocotylinea). This is incongruent with the polytomic topology inferred from 66 homologous series of morphological traits [32] and close relationship between Gastrocotylinea and Discocotylinea based on morphological characters and close relationship between Microcotylinea and Discocotylinea using large nuclear subunit ribosomal RNA gene [33]. The topology of the three Diplozoidae family genera, (Eudiplozoon, (Sindiplozoon, Paradiplozoon)), was also in disagreement with most previous studies $[9,12,14]$, except for the ML topology in Gao et al. [9]. In our phylogram, Paradiplozoon (Chinese) formed a sister group with Sindiplozoon (with a robust support value). This close relationship is also reflected in the similarity of skewness for the full genome and its elements (PCGs) (Fig. 1a, b), as well as the similarity of codon and amino acid usage patterns (Fig. 1e, f). However, pairwise similarity (Table 1), secondary structures (Figs. 3 and 4) and similarity of skewness (Fig. 1c) for the 22 tRNAs, as well as similarity of skewness for the two rRNAs (Fig. 1d), did not reflect this close intergeneric relationship. This is in agreement with our observation that all RNA sequences of these mitogenomes exhibit slighter mutational biases than the PCGs (Fig. 1g), which may be associated with the mutational constraints imposed by the need for formation of stem-loop secondary structures (i.e., base pairing between $\mathrm{A}$ and $\mathrm{T}, \mathrm{G}$ and C) [40].

\section{Conclusions}

Unlike other monogeneans, mitogenomes of the three diplozoids exhibit enigmatic strand-specific nucleotide biases for the full genome, PCGs, tRNAs and rRNAs (Fig. 1a-d), as well as unusual codon and amino acid usage patterns for PCGs (Fig. 1e, f). In that aspect, they are more similar to cestodes and trematodes than to other monogenean flatworms. We suspect that this unusual bias has also caused disproportionately long branches of the three diplozoids in the phylogram. Intergeneric relationships within the family Diplozoidae produced in this study, as well as the interrelationships of Discocotylinea, Microcotylinea, and Gastrocotylinea suborders, are in disagreement with previous results based on small molecular markers and morphological traits $[9,12,32,33]$. Therefore, our study might provide important new insights into the evolutionary history of the three genera and three suborders. However, as the three diplozoids exhibit unusual mitogenomic compositions, and as we had a limited number of diplozoid species at disposal for this analysis, we cannot reject with confidence the hypotheses put forward by the previous studies. Combined results of the sliding window, $\mathrm{dN} / \mathrm{dS}$ ratio and average sequence identity analyses indicate that nad2, atp6 and nad6 are the most variable PCGs, whereas cox1, nad1 and cytb are the most conserved PCGs. As cox 1 is often used as an universal barcode for species identification in general [62], as well as in monogeneans [63-66], our results suggest that its suitability for this task needs to be closely reassessed. Alternatively, we propose that nad2, atp6 and nad6 might be suitable markers for future diagnostics/ detection and population genetics studies of the family Diplozoidae. 


\section{Methods}

\section{Specimen collection and identification}

Multiple specimens belonging to three parasitic diplozoid species were obtained from gills of different fish species on three different locations in central China. The first species, Paradiplozoon opsariichthydis, was obtained from the Chinese hooksnout carp (Opsariichthys bidens Günther 1873) bought at a local market in Danjiangkou, Hubei Province $\left(32^{\circ} 82^{\prime} 50^{\prime \prime}\right.$ - 33 $81^{\prime} 50^{\prime \prime} \mathrm{N} ; 11^{\circ} 08^{\prime} 70^{\prime \prime}$ $11^{\circ} 18^{\prime} 60^{\prime \prime}$ E) on 18/Apr/2015. The second species, Eudiplozoon sp., was obtained from a fish specimen belonging to the Carassius auratus complex [71, 72] Linnaeus, 1758 (henceforth referred to as gibel carp) caught by fishermen in Tangxun Lake, Hubei Province $\left(30^{\circ} 22^{\prime} 56^{\prime \prime}-30^{\circ} 27^{\prime} 04^{\prime \prime}\right.$ N; $114^{\circ} 20^{\prime} 14^{\prime \prime}-114^{\circ} 23^{\prime} 08^{\prime \prime}$ E) on 22/May/2015. Samples belonging to the third species, Sindiplozoon sp., were collected from three different fish species, black carp (Mylopharyngodon piceus Richardson, 1846), Parabramis pekinensis (Basilewsky 1855), and Spinibarbus hollandi (Oshima 1919), caught by fishermen in the Mangtang Stream, Hunan Province $\left(27^{\circ} 29^{\prime} 26^{\prime \prime}-27^{\circ} 29^{\prime} 31^{\prime \prime} \mathrm{N} ; 109^{\circ}\right.$ $38^{\prime} 36^{\prime \prime}-109^{\circ} 38^{\prime} 51^{\prime \prime}$ E) on $9 / \mathrm{Jul} / 2016$. As the host fishes were dead when we obtained from markets/fishermen, and parasitic invertebrates are not covered by animal welfare laws, thus no permission was needed. Parasites were identified morphologically under a light microscope according to the traits commonly used for the Diplozoidae family (central hooks and clamps) [3, 34]. As described in Civanova et al. [12], one of the two opisthaptors of each parasite was cut off and soaked in $10 \%$ sodium dodecyl sulfate for $60 \mathrm{~min}$. After washing in distilled water, the opisthaptor was mounted on a microscope slide and fixed with a mixture of ammonium picrate and glycerin. Additionally, to confirm the taxonomic identity using molecular data, DNA was extracted from one of the two anterior parts of the parasite body, and used to amplify ITS-2 $r D N A$ gene using the universal eukaryotic primers [73]: D (5'-GGCTYRYGGNGTCGATGAAGAAC GCAG-3') and B1 (5'-GCCGGATCCGAATCCTGGT TAGTTTCTTTTCCT-3'). Finally, the remaining incomplete parasite bodies (one anterior part and one opisthaptor) of the three species were permanently stored as vouchers in $100 \%$ ethanol at the Parasitology and Coevolution Lab (room number 511), Institute of Hydrobiology, Chinese Academy of Sciences, Wuhan, China (Accession No.: IHB20180620001 for P. opsariichthydis, IHB20180620002 for Eudiplozoon sp., and IHB20180620003 for Sindiplozoon sp.).

\section{DNA extraction, amplification and sequencing}

Degenerate primer pairs (Additional file 12) were designed to match the generally conserved regions of mitochondrial genes and used to amplify and sequence these short conserved fragments. Based on these fragments, we then designed specific primers for the amplification and sequencing of the remaining mitogenomic sequences in several PCR steps. PCR was performed in a $20 \mu$ reaction mixture, containing $7.4 \mu \mathrm{l}$ dd $\mathrm{H}_{2} \mathrm{O}, 10 \mu \mathrm{l} 2 \times \mathrm{PCR}$ buffer $\left(\mathrm{Mg}^{2+}\right.$, dNTP plus, Takara, Dalian, China), $0.6 \mu \mathrm{l}$ of each primer, $0.4 \mu \mathrm{rTaq}$ polymerase (250 U, Takara), and $1 \mu \mathrm{l}$ of DNA template. Amplification was conducted under the following conditions: initial denaturation at $98{ }^{\circ} \mathrm{C}$ for $2 \mathrm{~min}$, followed by 40 cycles at $98{ }^{\circ} \mathrm{C}$ for $10 \mathrm{~s}, 48-60{ }^{\circ} \mathrm{C}$ for $15 \mathrm{~s}$, $68{ }^{\circ} \mathrm{C}$ for $1 \mathrm{~min} / \mathrm{kb}$, and a final extension at $68{ }^{\circ} \mathrm{C}$ for $10 \mathrm{~min}$. PCR products were sequenced bi-directionally on an ABI 3730 automatic sequencer using Sanger method. During the sequencing we paid close attention to electropherograms, carefully examining them for double peaks, or any other sign of the existence of two different sequences. All obtained fragments were BLASTed [74] to confirm that the amplicon is the actual target sequence.

\section{Sequence annotation and analyses}

After quality-proofing of the obtained fragments, the three mitogenomic sequences were assembled manually in a stepwise manner with the help of DNAstar v7.1 program [75]. The sequence of the $P$. opsariichthydis mitogenome could not be assembled into a full circular genome due to a gap of around $2000 \mathrm{bp}$ in the long non-coding region (LNR). All mitogenomes were annotated mainly following the procedure described before $[15,25,30,42]$. To determine the approximate boundaries of genes, all three mitogenomic sequences were aligned against a selected reference mitogenome, Pseudochauhanea macrorchis (Liu, Zhang \& Lin, 2001, NC_016950) [32], using MAFFT [76] integrated into Geneious [77]. Protein-coding genes (PCGs) were found by searching for ORFs (employing genetic code 9, echinoderm mitochondrial) and checking nucleotide alignments against the reference genome in Geneious. All 22 tRNAs were identified using ARWEN [78] and MITOS [79] web servers, and their secondary structures were visualized according to these results. Exceptions were trnC and trnK of Eudiplozoon sp., which were found by the alignment with orthologs in P. opsariichthydis and Eudiplozoon sp. mitogenomes. The two rRNAs, $r r n L$ and $r r n S$, were also initially identified using MITOS, and their precise boundaries determined via a comparison with homologs in Geneious. A home-made GUI-based program, MitoTool [80], was used to create GenBank submission files and tables with statistics for mitogenomes by parsing the annotations recorded in Word documents. Nucleotide (nt) composition and amino acid (aa) composition tables of all available monogenean mitogenomes were generated by MitoTool, and then used to make the broken line graph of skewness and $G+T$ content for nt, as well as stacked bar chart for amino acids in ggplot2 [81]. Codon usage and relative synonymous codon usage (RSCU) for twelve protein-encoding genes 
(PCGs) of the six polyopisthocotylids characterized so far were computed and sorted using MitoTool, and finally imported into ggplot2 to draw the RSCU figure. All scatter diagrams for the principal component analysis (PCA) and nucleotide skews were also drawn by ggplot2. Input files for the PCA of the codon usage pattern, as well as the aa usage pattern and the analyses of nucleotide skews for all available flatworm (free-living and parasitic) mitogenomes, were also generated by MitoTool. PASW 18.0 [82] was used to conduct principal component analysis and generate data for the scatter diagram. Non-synonymous (dN) / synonymous (dS) mutation rate ratios among the 12 PCGs of the three studied diplozoid mitogenomes were calculated with KaKs_Calculator [83] utilizing a modified Yang-Nielsen algorithm. DnaSP v5 [84] was employed to conduct the sliding window analysis: a sliding window of $200 \mathrm{bp}$ and a step size of $20 \mathrm{bp}$ was implemented to estimate the nucleotide divergence $\mathrm{Pi}$ between the mitogenomes of Sindiplozoon sp., P. opsariichthydis and Eudiplozoon sp.. Tandem Repeats Finder [85] was employed to find tandem repeats in the non-coding regions, and their secondary structures were predicted by Mfold software [86].

\section{Phylogenetic analyses}

Phylogenetic analyses were conducted using the three newly sequenced diplozoid mitogenomes and all 18 monogenean mitogenomes available in the GenBank (9/Nov/2017). As suggested in our previous study [42], two species of the order Tricladida, Crenobia alpina (Dana, 1766) (KP208776) and Obama sp. MAP-2014 (NC_026978), were used as outgroups, thus adding up to 23 mitogenomes in total (Additional file 13). Fasta files with nucleotide sequences for twelve protein-coding genes (PCGs) were extracted from GenBank files and translated into amino acid sequences (employing genetic code 9, echinoderm mitochondrial) using MitoTool as described before [15, 25, 30, 42, 87]. Amino acid sequences were aligned in batches and ambiguously aligned fragments removed from the concatenated alignment using MAFFT [76] and Gblocks 0.91b [88] (respectively) integrated into another GUI-based program compiled by us, BioSuite [89]. Phylogenetic analyses were performed using amino acid sequences of 12 PCGs. Phylogenetic analyses were conducted using two different algorithms: maximum likelihood (ML) and Bayesian inference (BI). Based on the Akaike information criterion, MTART $+\mathrm{I}+\mathrm{G}+\mathrm{F}$ was chosen as the optimal evolutionary model for the phylogenetic analysis, using ProtTest [90]. ML analysis was conducted in RaxML [91] using a ML + rapid bootstrap algorithm with 1000 replicates. As described in our recent paper [15], BI analysis was firstly carried out in MrBayes 3.2.6 [92] with default settings, and $5 \times 10^{6}$ metropolis-coupled MCMC generations, using a sub-optimal model $\mathrm{LG}+\mathrm{I}+\mathrm{G}+\mathrm{F}$ (the closest implemented model to the optimal MTART $+\mathrm{I}+\mathrm{G}+\mathrm{F}$ ). Stationarity was considered to be reached when the average standard deviation of split frequencies was below 0.01, ESS (estimated sample size) value was above 200, and PSRF (potential scale reduction factor) approached 1. Bayesian inference analyses with empirical model MTART and site-heterogeneous model with empirical matrixes CAT +MTART were conducted using PhyloBayes MPI 1.5a [93]. For each analysis, two MCMC chains were run after the removal of invariable sites from the alignment, and the analysis was stopped when the conditions considered to indicate a good run (PhyloBayes manual) were reached: maxdiff $<0.1$ and minimum effective size $>300$. Sequence alignment matrices and the resultant trees were deposited in TreeBASE repository [94] under the accession number 21941. Phylograms and gene orders were visualized and annotated by iTOL [95] with the help of several dataset files generated by MitoTool, as described in our recent papers $[15,30,96]$. Finally, based on the resultant optimal phylogram, we performed an ancestral character state inference for the gene orders in the subclass Polyopisthocotylea using MLGO web server [97] (ML algorithm) and TreeREx [98] (common interval algorithm).

\section{Additional files}

Additional file 1: Visual representation of the circular mitochondrial genomes of Paradiplozoon opsariichthydis, Sindiplozoon sp. and Eudiplozoon sp.. Protein-coding genes (12) are red, tRNAs (22) are yellow, rRNAs (2) are green, and non-coding regions are grey. (PDF 247 kb)

Additional file 2: Nucleotide composition and skewness comparison of different elements of the mitochondrial genomes of Paradiplozoon opsariichthydis, Sindiplozoon sp. and Eudiplozoon sp.. NCR: non-coding region; PCG: protein-coding gene. (XLSX 16 kb)

Additional file 3: Relative synonymous codon usage (RSCU) of six polyopisthocotylid mitogenomes. Codon families are labelled on the $x$-axis. Values on the top of the bars refer to amino acid usage. (PDF $273 \mathrm{~kb}$ )

Additional file 4: Summary of multiple alignments of tRNA genes in diplozoid mitogenomes. ALN: alignment; INUC: percent of identical nucleotides. (XLSX $12 \mathrm{~kb}$ )

Additional file 5: Secondary structure of the small non-coding regions in the mitogenomes of Paradiplozoon opsariichthydis, Sindiplozoon sp. and Eudiplozoon sp., and tandem repeats in the large non-coding regions in the genomes of Paradiplozoon opsariichthydis and Sindiplozoon sp.. (PDF $616 \mathrm{~kb}$ )

Additional file 6: Phylogenetic trees based on all four analyses. (PDF $411 \mathrm{~kb}$ )

Additional file 7: Light micrographs of the central hook and clamps of Paradiplozoon opsariichthydis. a. A row of clamps and one central hook under a $20 \times$ light microscope. b. Central hooks and clamps under a $10 \times$ light microscope. c. Another row of clamps and central hook under a $20 \times$ light microscope. d. Central hook and part of clamps under a $40 \times$ light microscope. (TIF $15208 \mathrm{~kb}$ )

Additional file 8: Light micrographs of central hooks and clamps of Eudiplozoon sp.. a. Central hooks and clamps under a 20x light microscope. b. Central hooks and clamps under a $20 \times$ confocal laser scanning microscope. c. A row of clamps and one central hook under a $40 \times$ light microscope. d. Another row of clamps and central hook under a 40× light microscope. (TIF $13034 \mathrm{~kb}$ )

Additional file 9: Light micrographs of central hooks and clamps of Sindiplozoon sp.. a. A row of clamps under a $20 \times$ light microscope. 
b. Another row of clamps under a $20 \times$ light microscope. c. All clamps under a $20 \times$ confocal laser scanning microscope. d. Central hooks under a 40x light microscope. (TIF 15007 kb)

Additional file 10: Phylogenetic tree based on 69 ITS-2 rDNA sequences using maximum-likelihood algorithm. (PDF 313 kb)

Additional file 11: General statistics (length and codons) for mitochondrial protein-coding genes and rRNAs of 21 monogeneans. Abbreviations of species name are combined initials of the genus and species name. (XLSX $13 \mathrm{~kb}$ )

Additional file 12: Primers used to amplify and sequence the mitochondrial genomes of Paradiplozoon opsariichthydis, Sindiplozoon sp. and Eudiplozoon sp.. (XLSX $11 \mathrm{~kb}$ )

Additional file 13: The list of monogenean species and outgroups used for comparative mitogenomic and phylogenetic analyses. (XLSX $15 \mathrm{~kb}$ )

\section{Abbreviations}

aa: amino acid; Bl: Bayesian inference; cbc: compensatory base changes dN: Non-synonymous mutation rate; dS: synonymous mutation rate; ITS: Internal transcribed spacer; LNR: Long non-coding region; ML: Maximum likelihood; nt: nucleotide; ORF: Open reading frame; PCA: Principal component analyses; PCGs: Protein-encoding genes; RSCU: Relative synonymous codon usage; SNR: Short non-coding region; TA*: Tandem repeat of the sequence TA; TR: Tandem repeat

\section{Acknowledgements}

The authors would like to thank Dr. Cong J. Hua and Bing W. Xi for the assistance in sampling the monogeneans.

\section{Funding}

This work was funded by the National Natural Science Foundation of China (31872604, 31572658), the Earmarked Fund for China Agriculture Research System (CARS-45-15), and the Major Scientific and Technological Innovation Project of Hubei Province (2015ABA045). The funders had no role in the design of the study, collection, analysis and interpretation of data, and in writing the manuscript.

\section{Availability of data and materials}

All data are fully available without restriction. The datasets supporting the conclusions of this article are included within the article and its additiona files. The three mitogenomic sequences are available from the GenBank under the accession numbers: MG458328, MG458326 and MG458327.

\section{Authors' contributions}

GTW, WXL, SGW, ML and DZ designed the study. DZ, HZ, JZ and RC conducted the experiments. DZ, WXL and IJ conducted the data analysis. DZ and IJ wrote the paper. All authors contributed comments to the final version of the manuscript. All authors read and approved the final manuscript.

\section{Ethics approval and consent to participate}

All experimental procedures involving animals were reviewed, approved and supervised by the Animal Care Committee of the Institute of Hydrobiology, Chinese Academy of Sciences. As the study did not involve any (live) vertebrates, and parasites are not among the regulated invertebrates, no special permits were required to retrieve and process the samples (EU Council Directive 86/609/EEC).

\section{Consent for publication}

Not applicable.

\section{Competing interests}

The authors declare that they have no competing interests.

\section{Publisher's Note}

Springer Nature remains neutral with regard to jurisdictional claims in published maps and institutional affiliations.

\section{Author details}

Key Laboratory of Aquaculture Disease Control, Ministry of Agriculture, and State Key Laboratory of Freshwater Ecology and Biotechnology, Institute of Hydrobiology, Chinese Academy of Sciences, Wuhan 430072, People's Republic of China. 'University of Chinese Academy of Sciences, Beijing, People's Republic of China. ${ }^{3}$ Bio-Transduction Lab, Biolake, Wuhan 430075, People's Republic of China.

Received: 1 April 2018 Accepted: 20 August 2018

Published online: 03 September 2018

\section{References}

1. Dinh Hoai T, Hutson KS. Reproductive strategies of the insidious fish ectoparasite, Neobenedenia sp. (Capsalidae: Monogenea). PLoS One. 2014; 9(9):e108801.

2. Sicard M, Desmarais E. Lambert A. Is the Octomacridae the sister family of the Diplozodae? Parasite. 2002;9(1):85-7.

3. Khotenovsky IA: The subclass octomacrinea Khotenovsky. Nauka, Leningrad; 1985: 262 [In Russian.].

4. Khotenovsky IA. Life cycle of several monogeneans of the genus Diplozoon. Parazitol Sb. 1977;27:35-43

5. Shimazu T, Kobayashi K, Tojo K, Besprozvannkh V, Ogawa K. Paradiplozoon skrjabini (Monogenea, Diplozoidae), an ectoparasite on the gills of freshwater fishes (Cyprinidae, Leuciscinae) of Japan and Primorsky Region, Russia: a morphological and molecular study. Bulletin of the National Museum of Nature and Science, Series A. 2015:41:137-54.

6. Bychowsky BE, Nagibina LF. On the systematics of the genus Diplozoon Nordmann (Monogenoidea). Zool Zhurnal. 1959;38(3):362-77.

7. Kawatsu H. Studies on the anemia of fish-IX. Hypochromic microcytic anemia of crucian carp caused by infestation with a trematode, Diplozoon nipponicum. Bull Japan Soc Sci Fish. 1978;44:1315-9.

8. Buchmann K, Bresciani J. Monogenea (Phylum Platyhelminthes). In: Woo PTK, editor. Fish diseases and disorders, Volume 1: Protozoan and Metazoan Infections. Wallingford, UK: CABI Publishing; 2006. p. 297-344

9. Gao Q, Chen MX, Yao WJ, Gao Y, Song Y, Wang GT, Wang MX, Nie P. Phylogeny of diplozoids in five genera of the subfamily Diplozoinae Palombi, 1949 as inferred from ITS-2 rDNA sequences. Parasitology. 2007:134:695-703.

10. Justine J-L. Cladistic study in the Monogenea (Platyhelminthes), based upon a parsimony analysis of spermiogenetic and spermatozoal ultrastructural characters. Int J Parasitol. 1991;21(7):821-38

11. MatejusovÁ I, KoubkovÁ B, D'Amelio S, Cunningham CO. Genetic characterization of six species of diplozoids (Monogenea; Diplozoidae). Parasitology. 2001;123(5):465-74.

12. Civanova K, Koyun M, Koubkova B. The molecular and morphometrical description of a new diplozoid species from the gills of the Garra rufa (Heckel, 1843) (Cyprinidae) from Turkey - including a commentary on taxonomic division of Diplozoidae. Parasitol Res. 2013;112(8):3053-62.

13. Avenant-Oldewage A, le Roux LE, Mashego SN, van Vuuren BJ. Paradiplozoon ichthyoxanthon n. sp. (Monogenea: Diplozoidae) from Labeobarbus aeneus (Cyprinidae) in the Vaal River, South Africa. J Helminthol. 2014;88(2):166-72.

14. Ahmad F, Fazili K, Sofi T, Waza A, Rashid R. Comparative molecular characterization of three Diplozoon species from fishes of Kashmir Valley. Agricultural Advances. 2015;4(7):65-83.

15. Zhang D, Zou H, Wu SG, Li M, Jakovlić I, Zhang J, Chen R, Wang GT, Li WX. Sequencing of the complete mitochondrial genome of a fish-parasitic flatworm Paratetraonchoides inermis (Platyhelminthes: Monogenea): tRNA gene arrangement reshuffling and implications for phylogeny. Parasit Vectors. 2017:10(1):462

16. Whittington ID, Cribb BW, Hamwood TE, Halliday JA. Host-specificity of monogenean (platyhelminth) parasites: a role for anterior adhesive areas? Int J Parasitol. 2000;30(3):305-20.

17. Sicard M, Desmarais E, Lambert A. Molecular characterization of Diplozoidae populations on five Cyprinidae species: consequences for host specificity. C r Acad Sci Sér. 2001:3:709-17.

18. Gelnar M, Sebelova S, Dusek L, Koubková B, Jurajda P, Zahrádková S Biodiversity of parasites in freshwater environment in relation to pollution. Parassitologia. 1997;39(3):189-99.

19. Matejusova I, Koubkova B, Cunningham CO. Identification of European diplozoids (Monogenea, Diplozoinae) by restriction digestion of the ribosomal RNA internal transcribed spacer. J Parasitol. 2004;90(4):817-22. 
20. Delsuc F, Tsagkogeorga G, Lartillot N, Philippe H. Additional molecular support for the new chordate phylogeny. Genesis. 2008;46(11):592-604.

21. Huyse T, Buchmann K, Littlewood DT. The mitochondrial genome of Gyrodactylus derjavinoides (Platyhelminthes: Monogenea) - a mitogenomic approach for Gyrodactylus species and strain identification. Gene. 2008; 417(1-2):27-34.

22. Gissi C, lannelli F, Pesole G. Evolution of the mitochondrial genome of Metazoa as exemplified by comparison of congeneric species. Heredity (Edinb). 2008;101(4):301-20

23. Wey-Fabrizius AR, Podsiadlowski L, Herlyn H, Hankeln T. Platyzoan mitochondrial genomes. Mol Phylogenet Evol. 2013;69(2):365-75.

24. Cameron SL. Insect mitochondrial genomics: implications for evolution and phylogeny. Annu Rev Entomol. 2014;59:95-117.

25. Zou H, Jakovlic I, Chen R, Zhang D, Zhang J, Li WX, Wang GT. The complete mitochondrial genome of parasitic nematode Camallanus cotti: extreme discontinuity in the rate of mitogenomic architecture evolution within the Chromadorea class. BMC Genomics. 2017;18(1):840

26. Mollaret I, Jamieson BG, Justine J-L. Phylogeny of the Monopisthocotylea and Polyopisthocotylea (Platyhelminthes) inferred from $28 \mathrm{~S}$ rDNA sequences. Int J Parasitol. 2000;30(2):171-85.

27. Smith DR, Keeling PJ. Mitochondrial and plastid genome architecture: Reoccurring themes, but significant differences at the extremes. Proc Natl Acad Sci U S A. 2015;112(33):10177-84.

28. Yin M, Zheng HX, Su J, Feng Z, McManus DP, Zhou XN, Jin L, Hu W. Codispersal of the blood fluke Schistosoma japonicum and Homo sapiens in the Neolithic Age. Sci Rep. 2015;5:18058.

29. Perkins EM, Donnellan SC, Bertozzi T, Whittington ID. Closing the mitochondrial circle on paraphyly of the Monogenea (Platyhelminthes) infers evolution in the diet of parasitic flatworms. Int J Parasitol. 2010;40(11):1237-45.

30. Li WX, Zhang D, Boyce K, Xi BW, Zou H, Wu SG, Li M, Wang GT. The complete mitochondrial DNA of three monozoic tapeworms in the Caryophyllidea: a mitogenomic perspective on the phylogeny of eucestodes. Parasit Vectors. 2017;10(1):314

31. Jia W-Z, Yan H-B, Guo A-J, Zhu X-Q, Wang Y-C, Shi W-G, Chen H-T, Zhan F, Zhang S-H, Fu B-Q. Complete mitochondrial genomes of Taenia multiceps, T. hydatigena and T. pisiformis: additional molecular markers for a tapeworm genus of human and animal health significance. BMC Genomics. 2010;11(1):1.

32. Boeger WA, Kritsky DC. Phylogenetic relationships of the Monogenoidea. In: Littlewood DTJ, Bray RA, editors. Interrelationships of the Platyhelminthes. London: Taylor \& Francis; 2001. p. 92-102.

33. Olson P, Littlewood D. Phylogenetics of the Monogenea-evidence from a medley of molecules. Int J Parasitol. 2002;32(3):233-44.

34. Wu B, Lang S, Wang WJ. Fauna Sinica: Platyhelminthes: Monogenea. Beijing: Science Press; 2000.

35. Poulin R. The evolution of monogenean diversity. Int J Parasitol. 2002;32(3): 245-54.

36. Šimková A, Morand S, Jobet E, Gelnar M, Verneau O. Molecular phylogeny of congeneric monogenean parasites (Dactylogyrus): a case of intrahost speciation. Evolution. 2004;58(5):1001.

37. Simkova A, Serbielle C, Pariselle A, Vanhove MP, Morand S. Speciation in Thaparocleidus (Monogenea: Dactylogyridae) parasitizing Asian Pangasiid catfishes. Biomed Res Int. 2013;2013:353956.

38. McMurray AA, Sulston JE, Quail MA. Short-insert libraries as a method of problem solving in genome sequencing. Genome Res. 1998;8(5):562-6.

39. Hu M, Jex AR, Campbell BE, Gasser RB. Long PCR amplification of the entire mitochondrial genome from individual helminths for direct sequencing. Nat Protoc. 2007;2(10):2339-44

40. Park JK, Kim KH, Kang S, Kim W, Eom KS, Littlewood DT. A common origin of complex life cycles in parasitic flatworms: evidence from the complete mitochondrial genome of Microcotyle sebastis (Monogenea: Platyhelminthes). BMC Evol Biol. 2007;7:11.

41. Zhang J, Wu X, Xie M, Li A. The complete mitochondrial genome of Pseudochauhanea macrorchis (Monogenea: Chauhaneidae) revealed a highly repetitive region and a gene rearrangement hot spot in Polyopisthocotylea. Mol Biol Rep. 2012;39(8):8115-25.

42. Zhang D, Zou H, Wu SG, Li M, Jakovlic I, Zhang J, Chen R, Wang GT, Li WX Sequencing, characterization and phylogenomics of the complete mitochondrial genome of Dactylogyrus lamellatus (Monogenea: Dactylogyridae). J Helminthol. 2017:1-12.

43. Le TH, Blair D, McManus DP. Mitochondrial genomes of parasitic flatworms. Trends Parasitol. 2002;18(5):206-13.
44. Zardoya R, Garrido-Pertierra A, Bautista JM. The complete nucleotide sequence of the mitochondrial DNA genome of the rainbow trout, Oncorhynchus mykiss. J Mol Evol. 1995;41(6):942-51.

45. Reyes A, Gissi C, Pesole G, Saccone C. Asymmetrical directional mutation pressure in the mitochondrial genome of mammals. Mol Biol Evol. 1998; 15(8):957-66.

46. Perseke M, Hetmank J, Bernt M, Stadler PF, Schlegel M, Bernhard D. The enigmatic mitochondrial genome of Rhabdopleura compacta (Pterobranchia) reveals insights into selection of an efficient tRNA system and supports monophyly of Ambulacraria. BMC Evol Biol. 2011;11(1):134.

47. Hassanin A, Léger N, Deutsch J. Evidence for multiple reversals of asymmetric mutational constraints during the evolution of the mitochondrial genome of Metazoa, and consequences for phylogenetic inferences. Syst Biol. 2005;54(2):277-98.

48. Bachmann L, Fromm B, de Azambuja LP, Boeger WA. The mitochondrial genome of the egg-laying flatworm Aglaiogyrodactylus forficulatus (Platyhelminthes: Monogenoidea). Parasit Vectors. 2016:9(1):1.

49. Kang S, Kim J, Lee J, Kim S, Min GS, Park JK. The complete mitochondrial genome of an ectoparasitic monopisthocotylean fluke Benedenia hoshinai (Monogenea: Platyhelminthes). Mitochondrial DNA. 2012;23(3):176-8.

50. Ye F, King SD, Cone DK, You P. The mitochondrial genome of Paragyrodactylus variegatus (Platyhelminthes: Monogenea): differences in major non-coding region and gene order compared to Gyrodactylus. Parasit Vectors. 2014;7:377.

51. Le TH, Pearson MS, Blair D, Dai N, Zhang LH, McManus DP. Complete mitochondrial genomes confirm the distinctiveness of the horse-dog and sheep-dog strains of Echinococcus granulosus. Parasitology. 2002;124(1):97112.

52. Carullo M, Xia X. An extensive study of mutation and selection on the wobble nucleotide in tRNA anticodons in fungal mitochondrial genomes. J Mol Evol. 2008;66(5):484-93.

53. Chen HX, Sun SC, Sundberg P, Ren WC, Norenburg JL. A comparative study of nemertean complete mitochondrial genomes, including two new ones for Nectonemertes of. mirabilis and Zygeupolia rubens, may elucidate the fundamental pattern for the phylum Nemertea. BMC Genomics. 2012;13:139.

54. Negrisolo E, Babbucci M, Patarnello T. The mitochondrial genome of the ascalaphid owlfly Libelloides macaronius and comparative evolutionary mitochondriomics of neuropterid insects. BMC Genomics. 2011;12(1):221.

55. Ye F, Easy RH, King SD, Cone DK, You P. Comparative analyses within Gyrodactylus (Platyhelminthes: Monogenea) mitochondrial genomes and conserved polymerase chain reaction primers for gyrodactylid mitochondrial DNA. J Fish Dis. 2016;

56. Lavrov DV, Brown WM, Boore JL. A novel type of RNA editing occurs in the mitochondrial tRNAs of the centipede Lithobius forficatus. Proc Natl Acad Sci U S A. 2000:97(25):13738-42

57. Cannone JJ, Subramanian S, Schnare MN, Collett JR, D'Souza LM, Du Y, Feng B, Lin N, Madabusi LV, Müller KM. The comparative RNA web (CRW) site: an online database of comparative sequence and structure information for ribosomal, intron, and other RNAs. BMC Bioinformatics. 2002;3(1):2.

58. Clark BF. The crystal structure of tRNA. J Biosci (Bangalore). 2006;31(4):453-7.

59. Zhang J, Wu X, Li Y, Zhao M, Xie M, Li A. The complete mitochondrial genome of Neobenedenia melleni (Platyhelminthes: Monogenea): mitochondrial gene content, arrangement and composition compared with two Benedenia species. Mol Biol Rep. 2014;41(10):6583-9.

60. Zou H, Zhang D, Li W, Zhou S, Wu S, Wang G. The complete mitochondrial genome of Gyrodactylus gurleyi (Platyhelminthes: Monogenea). Mitochondrial DNA Part B. 2016;1(1):383-5.

61. Zhang D, Zou H, Zhou S, Wu SG, Li WX, Wang GT. The complete mitochondrial genome of Gyrodactylus kobayashii (Platyhelminthes: Monogenea). Mitochondrial DNA Part B. 2016;1(1):146-7.

62. Hebert PD, Cywinska A, Ball SL. Biological identifications through DNA barcodes. Proc R Soc London, Ser B. 2003:270(1512):313-21.

63. Hansen H, Bachmann L, Bakke TA. Mitochondrial DNA variation of Gyrodacty/us spp.(Monogenea, Gyrodactylidae) populations infecting Atlantic salmon, grayling, and rainbow trout in Norway and Sweden. Int J Parasitol. 2003;33(13):1471-8.

64. Hansen H, Martinsen L, Bakke T, Bachmann L. The incongruence of nuclear and mitochondrial DNA variation supports conspecificity of the monogenean parasites Gyrodactylus salaris and G. thymalli. Parasitol. 2006;133(5):639-50.

65. Meinilä M, Kuusela J, Ziętara MS, Lumme J. Initial steps of speciation by geographic isolation and host switch in salmonid pathogen Gyrodactylus salaris (Monogenea: Gyrodactylidae). Int J Parasitol. 2004;34(4):515-26. 
66. Blasco-Costa I, Miguez-Lozano R, Sarabeev V, Balbuena JA. Molecular phylogeny of species of Ligophorus (Monogenea: Dactylogyridae) and their affinities within the Dactylogyridae. Parasitol Int. 2012;61(4):619-27.

67. Weber M, Wey-Fabrizius AR, Podsiadlowski L, Witek A, Schill RO, Sugar L, Herlyn H, Hankeln T. Phylogenetic analyses of endoparasitic Acanthocephala based on mitochondrial genomes suggest secondary loss of sensory organs. Mol Phylogenet Evol. 2013;66(1):182-9.

68. Liu GH, Shao R, Cai XQ, Li WW, Zhu XQ. Gnathostoma spinigerum Mitochondrial Genome Sequence: a Novel Gene Arrangement and its Phylogenetic Position within the Class Chromadorea. Sci Rep. 2015;5:12691.

69. Fernandez-Perez J, Nanton A, Ruiz-Ruano FJ, Camacho JPM, Mendez J. First complete female mitochondrial genome in four bivalve species genus Donax and their phylogenetic relationships within the Veneroida order. PLoS One. 2017;12(9):e0184464

70. Zhao G-H, Jia Y-Q, Cheng W-Y, Zhao W, Bian Q-Q, Liu G-H. Characterization of the complete mitochondrial genomes of Nematodirus oiratianus and Nematodirus spathiger of small ruminants. Parasit Vectors. 2014;7(1):319.

71. Jakovlic I, Gui JF. Recent invasion and low level of divergence between diploid and triploid forms of Carassius auratus complex in Croatia. Genetica. 2011;139(6):789-804.

72. Takada M, Tachihara K, Kon T, Yamamoto G, Ki I, Miya M, Nishida M. Biogeography and evolution of the Carassius auratus-complex in East Asia. BMC Evol Biol. 2010;10(1):7.

73. Baehellerie J-P, Qu L-H. Ribosomal RNA probes for detection and identification of species. In: Hyde JE, editor. Protocols in molecular parasitology. New Jersey: Humana Press; 1993. p. 249-63.

74. Altschul SF, Gish W, Miller W, Myers EW, Lipman DJ. Basic local alignment search tool. J Mol Biol. 1990;215(3):403-10.

75. Burland TG. DNASTAR's Lasergene sequence analysis software. Methods Mol Biol. 2000;132:71-91.

76. Katoh K, Standley DM. MAFFT multiple sequence alignment software version 7: improvements in performance and usability. Mol Biol Evol. 2013;30(4):772-80.

77. Kearse M, Moir R, Wilson A, Stones-Havas S, Cheung M, Sturrock S, Buxton S, Cooper A, Markowitz S, Duran C, Thierer T, Ashton B, Meintjes P Drummond A. Geneious Basic: an integrated and extendable desktop software platform for the organization and analysis of sequence data. Bioinformatics. 2012;28(12):1647-9.

78. Laslett D, Canback B. ARWEN: a program to detect tRNA genes in metazoan mitochondrial nucleotide sequences. Bioinformatics. 2008;24(2):172-5.

79. Bernt M, Donath A, Juhling F, Externbrink F, Florentz C, Fritzsch G, Putz J, Middendorf M, Stadler PF. MITOS: improved de novo metazoan mitochondrial genome annotation. Mol Phylogenet Evol. 2013;69(2):313-9.

80. Zhang D. MitoTool software. 2016. https://github.com/dongzhang0725/ MitoTool. Accessed 22 July 2018

81. Hadley W. ggplot2: Elegant graphics for data analysis. 2009.

82. Allen PJ, Bennett K. PASW statistics by SPSS: A practical guide: Version 18.0. Melbourne, Australia: Cengage Learning Press; 2010.

83. Zhang Z, Li J, Zhao X-Q, Wang J, Wong GK-S, Yu J. KaKs_Calculator: calculating Ka and Ks through model selection and model averaging. Genomics Proteomics Bioinformatics. 2006;4(4):259-63.

84. Librado P, Rozas J. DnaSP v5: a software for comprehensive analysis of DNA polymorphism data. Bioinformatics. 2009;25(11):1451-2

85. Benson $\mathrm{G}$. Tandem repeats finder: a program to analyze DNA sequences. Nucleic Acids Res. 1999;27(2):573.

86. Zuker M. Mfold web server for nucleic acid folding and hybridization prediction. Nucleic Acids Res. 2003;31(13):3406-15.

87. Liu F-F, Li Y-P, Jakovlic I, Yuan X-Q. Tandem duplication of two tRNA genes in the mitochondrial genome of Tagiades vajuna (Lepidoptera: Hesperiidae). Eur J Entomol. 2017;114:407-15.

88. Talavera G, Castresana J. Improvement of phylogenies after removing divergent and ambiguously aligned blocks from protein sequence alignments. Syst Biol. 2007;56(4):564-77.

89. Zhang D. BioSuite software. 2016. https://github.com/dongzhang0725/ BioSuite. Accessed 22 July 2018.

90. Abascal F, Zardoya R, Posada D. ProtTest: selection of best-fit models of protein evolution. Bioinformatics. 2005;21(9):2104-5.

91. Stamatakis A. RAxML version 8: a tool for phylogenetic analysis and postanalysis of large phylogenies. Bioinformatics. 2014;30:1312-3.

92. Ronquist F, Teslenko M, van der Mark P, Ayres DL, Darling A, Höhna S, Larget B, Liu L, Suchard MA, Huelsenbeck JP. MrBayes 3.2: efficient Bayesian phylogenetic inference and model choice across a large model space. Syst Biol. 2012:61(3):539-42

93. Lartillot N, Rodrigue N, Stubbs D, Richer J. PhyloBayes MPI: phylogenetic reconstruction with infinite mixtures of profiles in a parallel environment. Syst Biol. 2013;62(4):611-5.

94. Sanderson M, Donoghue M, Piel W, Eriksson T. TreeBASE: a prototype database of phylogenetic analyses and an interactive tool for browsing the phylogeny of life. Am J Bot. 1994;81(6):183.

95. Letunic I, Bork P. Interactive tree of life (iTOL) v3: an online tool for the display and annotation of phylogenetic and other trees. Nucleic Acids Res. 2016:44(W1):W242-5.

96. Li WX, Fu PP, Zhang D, Boyce K, Xi BW, Zou H, Li M, Wu SG, Wang GT. Comparative mitogenomics supports synonymy of the genera Ligula and Digramma (Cestoda: Diphyllobothriidae). Parasit Vectors. 2018;11(1):324.

97. Hu F, Zhou J, Zhou L, Tang J. Probabilistic reconstruction of ancestral gene orders with insertions and deletions. IEEE/ACM Trans Comput Biol. Bioinformatics. 2014;11(4):667-72.

98. Bernt $M$, Merkle D, Middendorf M. An algorithm for inferring mitogenome rearrangements in a phylogenetic tree. In: Nelson CE, Vialette $S$, editors. Comparative Genomics, International Workshop, RECOMB-CG 2008, Proceedings of Lecture Notes in Bioinformatics. Berlin: Springer; 2008. p. 143-57.
Ready to submit your research? Choose BMC and benefit from:

- fast, convenient online submission

- thorough peer review by experienced researchers in your field

- rapid publication on acceptance

- support for research data, including large and complex data types

- gold Open Access which fosters wider collaboration and increased citations

- maximum visibility for your research: over $100 \mathrm{M}$ website views per year

At BMC, research is always in progress.

Learn more biomedcentral.com/submissions 